\title{
IN PURSUIT OF OUR ANCESTORS' HAND LATERALITY
}

\author{
Amèlia Bargalló ${ }^{1}$, Marina Mosquera ${ }^{3,2}$, Sergi Lozano ${ }^{2,3}$ \\ ${ }^{1}$ University College London, Institute Archaeology, London, Great Britain. \\ ${ }^{2}$ IPHES, Institut Català de Paleoecologia Humana i Evolució Social, Tarragona, Spain \\ ${ }^{3}$ Area de Prehistoria, Universitat Rovira i Virgili (URV), Tarragona, Spain \\ Corresponding author: ameliabarg@gmail.com
}

\begin{abstract}
The aim of this paper is to apply a previously published method (Bargalló and Mosquera, 2014) to the archaeological record, allowing us to identify the hand laterality of our ancestors and determine when and how this feature, which is exhibited most strongly in humans, appeared in our evolutionary history. The method focuses on identifying handedness by looking at the technical features of the flakes produced by a single knapper, and discovering how many flakes are required to ascertain their hand preference.
\end{abstract}

This method can potentially be applied to the majority of archaeological sites, since flakes are the most abundant stone tools, and stone tools are the most widespread and widely-preserved remains from prehistory. For our study, we selected two Spanish sites: Gran Dolina-TD10.1 (Atapuerca) and Abric Romaní (Barcelona), which were occupied by pre-Neanderthal and Neanderthal populations, respectively.

Our analyses indicate that a minimum number of $\&$ eight flakes produced by the same knapper is required to ascertain their hand preference. Even though this figure is relatively low, it is quite difficult to obtain from many archaeological sites. In addition, there is no single technical feature that provides information about handedness, instead 
there is a combination of eight technical features, localised on the striking platforms and ventral surfaces. The raw material is not relevant where good quality rocks are used, in this case quartzite and flint, since most of them retain the technical features required for the analysis. Expertise is not an issue either, since the technical features analysed here only correlate with handedness (Bargalló and Mosquera, 2014). Our results allow us to tentatively identify one right-handed knapper among the pre-Neanderthals of level TD10.1 at Gran Dolina (Atapuerca), while four of the five Neanderthals analysed from Abric Romaní were right-handed. The hand preference of the fifth knapper from that location (AR5) remains unclear.

Keywords: Hand laterality, flakes, lithic technology, Atapuerca, Abric Romaní

\section{Introduction}

Laterality is the preference that living beings display for one half of the body over the other. This organisation settles in the structure of the brain, the organ that designates the role played by each extremity when performing a task.

Hand laterality is well known in our species, Homo sapiens. Various studies point to about $97 \%$ of the current population being lateralised, among which between $85 \%$ and $90 \%$ of individuals are right-handed, and between $10 \%$ and $15 \%$ are left-handed, depending on whether the communities are preindustrial, illiterate, and so on (Annett, 2002; Uomini, 2009). Hand laterality in apes has also been studied (Hopkins, 1996; McGrew and Marchant, 1997, 2001; Hopkins and Cantalupo, 2005), but it is less 
marked than human handedness and depends on several environmental and social conditions (Mosquera et al., 2007; Llorente et al., 2009, 2011). According to Llorente and colleagues: "...there must have been continuity in the evolution of handedness, at least between apes (chimpanzees) and the hominin family" (2011:569. Translated by us). However, the subject is not as straightforward as simply being right- or left-handed, since some studies have highlighted the fact that chimpanzees become more and more lateralised as the task to be done becomes increasingly complex. This condition also leads to an increase of in their technological behaviour, which has been interpreted as a landmark in the evolution of our hominin clade (Mosquera et al., 2012).

In fact, some researchers support that the most widespread tasks undertaken by humans are those where both hands play different roles: e.g., cutting, where one hand holds the matter to be cut, and the other uses the knife to do the actual cutting. In addition, cutting is not usually needed in the world of apes (Schick and Toth, 2009), which may have marked a strong difference between their ancestors and hominins. These type of tasks are also known as bimanual complementary tasks (McGrew and Marchant, 1999), bimanual complex tasks (Hopkins et al., 2004), and complementary role differentiation tasks (Uomini, 2009), which are indeed the most complex, as well as the most lateralising tasks, as demonstrated by Uomini (2009) in her experimental study with humans. Interpretation has led to the view that there is a feedback mechanism in the origin of handedness, where the recurring use of one hand gives it more skills compared with the other, in turn favouring the preferential use of the "skilled" hand. Both skill and practice reinforce handedness, a trait that may have favoured brain lateralisation (Teixeira and Okazaki, 2007). From a phylogenetic point of view, hand laterality may have been on the increase since the earliest hominins, as far back as Australopithecus 
(Mosquera et al., 2012). In this sense, cut-marks found at Dikika (Ethiopia) from $3.3 \mathrm{my}$ ago (McPherron et al., 2010) do not inform us about hand laterality, but they are byproducts of bimanual complementary tasks (i.e., cutting, defleshing), which reinforce our hypothesis.

The issue then, is to ascertain when handedness evolved in our hominin clade. Previous approaches to the question of hand laterality in our ancestors mostly focused on the hominin remains recorded from certain sites. Such is the case $\theta f$ in the dental-wear studies ef-with the so-called use of the third hand ("stuff and cut") in some of the preNeanderthal individuals deposited at the Sima de los Huesos site (Atapuerca, Spain) (Bermúdez et al., 1988, 2003; Lozano et al., 2009). Other studies have centred on the endocrania (Poza-Rey, 2015), humerus and other limb bones (Carretero, et al., 1997; Lazenby, 2002; Shaw, 2011). All these studies point to a similar handedness in Neanderthals as is found in modern humans (Frayer et al., 2010; Fiore et al., 2015). For its part, the pre-Neanderthal population of Sima de los Huesos (until recently, Homo heidelbergensis) from 450,000 years ago, is under debate: some researchers find evidences enough to interpret a similar pattern as in modern humans (Frayer et al., 2012), and others find noł well-defined brain lateralization (Poza-Rey et al., 2015).

In fact, the relation between brain asymmetry and hand laterality is not definitively solved (see Poza-Rey et al., 2015 for debate), and even just at the paleoanthropological level we may obtain divergent results. As mentioned, several studies pointed out that hand laterality (right-handedness) of Sima de los Huesos hominins may be identified in five 5 individuals by means of labial striations of the frontal dentition (Bermúdez et al., 1988; 2003; Lozano et al., 2009). However, in their recent publication on skulls from 
Sima de los Huesos (Atapuerca, Spain), Poza-Rey and colleagues (2015) have compared these data with the brain endocasts asymmetries found in four of the skulls to which some of that dentition belongs: crania/endocrania 16, 10, 9 and 6. Individual 16 and 6 did not show a right-handed manual preference in their endocasts asymmetries, but individual 16 shows dental striations to the left, while individual 6 shows dental striations to the right. Individuals 10 and 9 demonstarated right-handed manual preferences in their endocasts asymmetries, both associated with dental striations to the right. The authors suggest that the discrepancy obtained in individual 6 may be the result of ambidextrous handedness, but also a product of learning by imitation-

Anyway, hominin remains are scarce in the archaeological record, and they do not always include the body parts that give us information on this matter. Tests have been carried out on the direction and trajectory of the cut-marks accidentally left on bone surfaces by the stone tools used by hominins when processing prey for consumption (Bromage and Boyde, 1984; Bromage et al., 1991;). However, the results of this method have been also contested (Pickering et al., 2008).

For this study we have used the only remains that appear commonly at the majority of Pleistocene archaeological sites: stone tools. Because they are the most abundant remains at this type of sites, they can be an excellent source of information.

One approach that uses stone tools is use-wear analyses, the study of the use-wear developed along the edges of stone tools during use. Use-wear studies have revealed that one of the pre-Neanderthals that used tools to cut the meat off a carcass at the Middle Pleistocene Acheulean site of Galería (Atapuerca, Spain) was right-handed 
(Ollé, 2003). This type of study can be successful in identifying the hand preference of the user, but the approach requires that the tools themselves were both sufficiently used and well preserved.

Determining hand laterality through the technical study of flakes has been approached from two different perspectives: the knapping method used to produce the flakes (Toth, 1985), and the analyses of a single technical feature (Rugg and Mullane, 2001; Domínguez-Ballesteros and Arrizabalaga, 2015). Both of these approaches have been discussed and their results questioned because of the methods used (see Patterson and Sollberger, 1986, and Pobiner, 1999 for Toth, 1985, and Bargalló and Mosquera, 2014 for Rugg and Mullane, 2001).

In this paper, we apply the method we previously published, on how to identify handedness through the technical features of the flakes obtained by a knapper (Bargalló and Mosquera, 2014), with the aim of finding out how many flakes produced by a single Pleistocene knapper are needed to ascertain his/her hand preference. As mentioned previously, the benefit of this method is that it can potentially be applied to the majority of archaeological sites.

To do this, we selected two Spanish sites: Gran Dolina-TD10.1 (Atapuerca) and Abric Romaní (Barcelona), which were occupied by pre-Neanderthal and Neanderthal populations, respectively. In both species, the handedness of some individuals has been identified, so this study serves to both confirm the previous results and to test the reliability of this method when applied to older sites and hominin species, until the first hominin species that was completely lateralised is found, as well as any evolution in 
that process. Furthermore, given that the TD10-1 archaeological record was made by pre-Neanderthal populations peri-contemporary to that of $\mathrm{SH}$, our results may provide more evidence on the current debate.

\section{Method}

In Bargalló and Mosquera (2014) we presented a new method for inferring handedness from lithic evidence. The study was conducted by means of an experimental programme in stone knapping, after which the resulting lithic flakes were analysed. These flakes were produced by 15 inexpert knappers (eight right-handed and seven left-handed), because we were not able to find a statistically significant number of left-handed expert knappers. We considered inexpert knappers to include individuals who had never struck two pebbles together, as well as individuals who were quite familiar with prehistoric tools and had had some degree of practice. Importantly, the Mann-Whitney U test proved that all of them produced flakes with the same technical features concerning handedness, meaning that, within this sample group, expertise was not a factor that affected the presence or absence of these technical features analysed to determine hand laterality. On the contrary, expertise clearly affects the quality of the flakes in technological terms (i.e., longer, sharper edges, regular morphologies, etc.). The results of the experiment indicate that no single variable can be used to determine the laterality of the knapper, but instead this requires a combination of several variables. Furthermore, not all flakes display the entire set of significant features. The conclusion of this study is, therefore, that it is not possible to determine the hand preference of a knapper through a single variable present on their flakes, but it may be possible to 
determine his or her laterality by examining a combination of technical variables on a number of their pieces.

\section{Experimental sample}

The experimental sample corresponds to that published by Bargalló and Mosquera (2014). This experimental sample included 1,774 pieces knapped by seven left-handed and eight right-handed individuals. Of these, 1,159 were flakes and broken flakes, and 615 were fragments of flake and angular knapping fragments. The latter were not analysed, since they did not retain the necessary technological features. Of the 1,159 flakes and broken flakes, $629(54.23 \%)$ were produced by right-handers and 530 $(45.76 \%)$ by left-handers. The knapper who produced the fewest flakes made 49 pieces, and the knapper who generated the most flakes made 140 (Table 1). All the flakes were created from the same type of flint as used by $H$. neandertalensis at the Abric Romaní site (Barcelona, Spain) (Gómez de Soler, 2007; Carbonell, 2012; Soto et al., 2014).

Table 1

Handedness analysis

According to Bargalló and Mosquera (2014), only eight technical features from the complete catalogue of characteristics are informative to ascertain the hand laterality of the knapper. However, given that many pieces do not show the eight technical features indicative of hand preference, and also that the technical characteristics of a single piece 
may be the result of chance, a number of flakes knapped by the same individual must be analysed (Figure 1).

Figure 1

The following are the eight technical features and their variables $(n=21)$ that provide information about handedness:

a) Ventral surface:

1. Location of the ridge on the bulb, recorded by Rugg and Mullane (2001) as "skew". This small ridge starts at the impact point and runs along the cone of percussion, the proximal part of the whole bulb. It may be located to the right or left.

2. Location of the éraillure scars on the cone. These are small squamae that sometimes accidentally appear in the bulb. If present, they may be centred, or located to the right or left.

3. Location of the hackles. Small hackles may appear near the edges of the ventral surface. They may be distal, right or left located.

4. Location of the ripples. Long curved wrinkles that appear along the ventral surface and follow the detaching axis of the flake. They may be located distally, or to the right or left.

5. Orientation of the extracting axis of the flake. This may be right or left-oriented

b) Striking platform:

1. Location of the impact point on the striking platform. This may be right or left located.

2. Inclination of the striking platform. It may be to the right, left, or sinuous 
3. Morphology of the striking platform. This may be platform (plan), linear (lineal), or punctiform (pointed).

Figure 2

The correspondence analyses performed at Bargalló and Mosquera (2014) (Figure 2) showed that these features clearly allow the right-handed and left-handed knappers from the experiment to be distinguished. The first two factors explain $55.56 \%$ of the variability (factor 1:36.57\%, factor 2:18.99\%). In Figure 2 all the left-handed knappers are placed above factor 2, and the right-handed knappers are placed below factor 2 . Therefore, left-handed knappers tend to produce ripples $(39.39 \%)$, hackles $(31.79 \%)$, the ridge of the cone of percussion $(42.41 \%)$, the éraillure scars $(15.67 \%)$, and the impact points $(88.34 \%$ of the total relative inertia) on the left side of the flake. Interestingly they also tend to detach flakes with the striking platform sloped towards the right side of the piece (33.81\% of the total relative inertia). In contrast, right-handed knappers tend to form ripples (36\%), hackles (29.49\%), the ridge of the cone of percussion (49.59\%), the éraillure scars $(25.78 \%)$, and the impact points $(49.58 \%$ of the total relative inertia) on the right side of the flake. As opposed to left-handers, righthanded knappers tend to detach flakes with the striking platform sloped towards the leftside of the piece $(45.89 \%$ of the total relative inertia).

This work is based on the fact that the patterns of the experimental knappers help us identify the handedness of prehistoric knappers, as the archaeological samples are expected to follow the same patterns as the experimental ones (Figure 2). 


\section{Refit analysis}

In order to apply this method to the archaeological record, we need to find flakes detached by the same knapper. This can only be achieved by means of searching refits from knapping sequences of cores, which is a rather complicated process in many archaeological deposits. Although refits do not fully guarantee that only one knapper exploited one core, it is the best approach under the circumstances. Therefore, the first step is to search for as many refits as possible in archaeological samples.

In this study, we only analysed archaeological pieces longer than $10 \mathrm{~mm}$. Depending on the type of raw material, the archaeological assemblage needs to be classified into Raw Material Units (RMU; Roebroeks, 1988; Schäfer, 1990; Odell, 2004; Vaquero, 2008) and Minimum Analytical Nodules (MAN) (Bleed, 2004; Hall, 2004; Larson, 2004; Odell, 2004; Copper and Qiu, 2006). RMU are the blanks from which one, two or several cores may be exploited by different knappers. For example, these may be big blanks of flint that are fragmented in order to allow the knappers to take a piece and start the process of stone tool production. Archaeologically, we are unlikely to obtain the entire refit of the blank, since they were often large fragments selected, transported, knapped, abandoned, reused, and so on. Only workshops provide the chance of refitting a whole RMU. For their part, the MAN are each of the cores knapped. For example, a cobble knapped into a discoid is one MAN, as is each of the flint-knapped fragments from the abovementioned blank. Archaeologically, MAN are easier to complete by refitting than RMU, although the occupational traits of the sites, their post-depositional conditions, as well as the area excavated usually make this task difficult. Although 
theoretically the distinction between RMU and MAN is clear, archaeologically it is not always easy to determine whether a particular variety of raw material belongs to a RMU or a MAN. Therefore, throughout this work we will use the general term RMU. Both RMU and MAN allow us to identify the single cobbles/blanks from which the flakes were detached, and indeed, the single knapping events. Associating flakes into RMU and MAN is based on the macroscopic features of the artefacts (e.g., grain-size and colour of the cortical and non-cortical surface, internal inclusions such as microfossils, fractures, and veins) (Schäfer, 1990; Roebroeks, 1998; Odell, 2004; Vaquero, 2008).

Once the pieces have been grouped into RMU and/or MAN, the refitting process begins. There are 3 three types of refits: flakes detached in production/knapping sequences (refits sensu stricto), breakages (conjoins), and modifications (small pieces detached when retouching a flake) (Cziesla, 1990). In this study, only flakes coming from production sequences (refits) have been used, and only those that refit together.

\section{Data analysis}

In this study, we applied a multivariate statistical analysis (Correspondence analysis) using the program PAST (Paleontological Statistics Software) to identify the hand laterality of prehistoric knappers by comparing them with the experimental sample (Hammer, Harper and Ryan, 2001, 2008). More conventional, classification methodologies were also considered and evaluated using the experimental data. Specifically, we fitted our data with a Binary Logistic Regression and applied a simple 
Machine Learning algorithm (i.e., k- nearest neighbours). In both cases, the performance of the resulting classifiers could not significantly outperform the null model (i.e., random laterality attribution).

\section{Archaeological Material}

Gran Dolina TD10.1 (Atapuerca, Spain)

Gran Dolina is one of the eavities caves located at Sierra de Atapuerca, in the north of the Iberian Peninsula, near the city of Burgos. It is filled with $18 \mathrm{~m}$ of sediments divided into 11 lithostratigraphic units named TD1 to TD10, from bottom to top, and with a chronology ranging from the Early to Middle Pleistocene (Berger et al., 2008; Falguères et al., 2013; Arnold et al., 2014; Arnold and Demuro, 2015). In this work, we looked at the lithic remains of subunit TD10.1, which has a mean date of $244-337 \pm 29 \mathrm{ka}$ (Falguères et al., 1999, 2013; Berger et al., 2008; Rodríguez et al., 2011), but may be closer to $350 \mathrm{ka}$ (Moreno et al., in press).

Up to now, TD10.1 has been the richest subunit of not only Gran Dolina, but all the Sierra de Atapuerca sites, both in terms of lithic and faunal remains. The subunit has yielded roughly 21,000 lithic artefacts and 48,000 faunal remains, most of them near the north and east sectors of the excavation (Ollé et al., 2013). The lithic remains probably represent the local-scale evolution from Mode 2 to Mode 3 technology at Sierra de Atapuerca. While the lithic remains from upper TD10.1 show features typical of the 
Mode 2 to Mode 3 transition, the main archaeological assemblage of this subunit comprises centripetal cores, with diverse and standardised reduction sequences aimed at obtaining small and medium-sized flakes, and a number of Levallois cores combined with typical Mode 2 elements, such as large cutting tools (Rodríguez-Álvarez, 1997; Carbonell et al, 2001; Rodríguez-Álvarez, 2004; Ollé et al., 2013).

Up to now, 42 RMU of quartz $(n=215)$, and 148 RMU of quartzite ( $n=869)$ have been identified from subunit TD10.1. From among these, it has been possible to identify 15 quartz connections (seven refits and eight conjoins), and 72 quartzite connections (38 refits and 34 conjoins) (López-Ortega et al, 2015). Of these, 80 flakes and broken flakes of quartzite, belonging to 34 refit groups, are useful for our purposes (Figure 3). Two to five refitting flakes form most of these groups. This means that we have as many as 5 five flakes produced by a single knapper.

Figure 3

Abric Romaní (Barcelona, Spain)

The Abric Romaní rock shelter is located in the NE of the Iberian Peninsula, approximately $50 \mathrm{~km}$ west of Barcelona. The site is located in the town of Capellades, in the tufa formations that rise on the right bank of the Anoia River. The stratigraphy is composed of $20 \mathrm{~m}$ of well-stratified travertine sediments dated by U-Series as being between 40 and $70 \mathrm{ka}$ (Vaquero et al., 2013). 
The archaeological units tested for this study are levels $\mathrm{J}$ and $\mathrm{M}$, aged between 45 and 54 ka, which also show well-defined discrete accumulations (Vaquero and Pastó, 2001). Technologically, the lithic assemblage of both levels $\mathrm{J}$ and $\mathrm{M}$ correspond to Mode 3, here characterised by discoid and expeditious knapping methods.

Level $\mathrm{J}$ has yielded 7,000 lithic artefacts, and 8,460 faunal remains. There are two main archaeostratigraphic units: sublevels $\mathrm{Ja}$ and $\mathrm{Jb}$, which have been distinguished only in the central area of the occupation. The U-series dates are $c .49 \mathrm{ka} \mathrm{BP}$ for the overlying tufa $(49.3 \pm 1.6$ and $49.2 \pm 2.9 \mathrm{ka} \mathrm{BP})$ and around $50 \mathrm{ka} \mathrm{BP}(50.0 \pm 1.6$ and $50.8 \pm 0.8$ ka BP) for the underlying tufa (Bischoff et al., 1988). In addition, a charcoal sample has been dated as $47.1 \pm 2.1{ }^{14} \mathrm{C}$ ka BP (NZA-2316) (Vaquero et al., 2012). According to the refits and the macroscopic characteristics of the raw materials, more than 500 RMU have been identified, each corresponding to a singular technical event. Moreover, 262 refitting groups, totalling 719 artefacts, have been found. In addition, level J has also yielded 50 hearths that seem to have spatially structured the site.

The tufa layer immediately above level M is dated at around $51.8 \pm 1.4 \mathrm{ka}$ BP (Bischoff et al., 1988; Vallverdú et al., 2012). The number of recorded archaeological remains is 18,946, of which 7,614 are faunal remains, 6,084 are lithic remains, 114 are wood imprints, 260 charcoal fragments and 37 hearths. In level $\mathrm{M}$ it has been possible to identify 76 RMU (under study). Moreover, 216 refitting groups, totalling 827 artefacts, have been found.

We have selected the refit groups with the most connecting flakes from a single core (MAN): one refit group from level Ja and seven refit groups from level M. All of them 
are flint. The smallest refit comprises 5 five flakes (AR3), while the largest is made up of 36 flakes (AR8) (Figure 4).

Figure 4

\section{Results}

The total sample set analysed comprised 1,355 flakes and broken flakes. Of these, 80 are from Gran Dolina (level TD10.1), 116 from Abric Romaní (level Ja and M) and 1,159 are from the experimental programme. Of the 1,355 pieces, 971 were complete flakes and 384 were broken flakes.

Tables 2 and 3 show the frequency at which the technical features of hand preference appear in the experimental sample together with Abric Romaní refit groups (Table 2), and Gran Dolina refit groups (Table 3). Interestingly, there are differences between the archaeological and experimental samples: $63 \%$ of the variables included in the technical features were not identified in any of the 80 flakes from level TD10.1 of Gran Dolina, and $27 \%$ of these variables were not identified in any of the 116 flakes from Abric Romaní. In contrast, just $3.26 \%$ of the variables could not be identified in any of the 1,159 experimental flakes. Furthermore, two variables of the technical features were not identified in any of the 196 archaeological flakes analysed: the distal location of hackles, and the sinuous inclination of the striking platform. Both these variables tended to appear in low frequencies in the experimental sample. Therefore, and taking into account the figures, it is likely that the presence/absence of some of the variables is directly linked to the number of flakes analysed: the more flakes detached by a single 
knapper, the more the possibilities of them containing all the variables included in each technical feature. The frequencies of each technical feature will be used in the correspondence analysis to identify the hand laterality of prehistoric knappers.

Table 2

Table 3

In order to ascertain the minimum number of flakes required to identify at $100 \%$ confidence the hand laterality of the knapper, we first performed a correspondence analysis, including all the archaeological and experimental samples. Figure 5 shows all the samples, and the way the archaeological groups of refits are located around the experimental ones. Compared to Figure 2 (only experimental samples) we can see that both left- and right-handed experimental knappers situate closer, concentrate, hence losing their spatial variability. This is probably because there are too few flakes in some of the archaeological refits, some of them having just two or three refit flakes.

Figure 5

Because of this distortion in the distribution pattern of the experimental groups, a second correspondence analysis was undertaken, this time excluding all archaeological refit groups with less than five flakes. By doing this we lose most of the Gran Dolina refit groups, since just one (GD29) comprises five flakes. Figure 6 shows the distribution of all the remaining samples, which is more similar to the experimentalonly pattern (Figure 2). Although the relative position of the right- and left-handed samples is correct (right-handers above the $\mathrm{X}$ axis, left-handers below), the 
experimental samples maintain the distorted pattern, particularly the position of the sample $\mathrm{R}-\mathrm{Nu}$ (a right-handed participant), which is below the $\mathrm{X}$ axis, in a similar position to some of the left-handed participants. In other words, individual R-Nu locates outside the sector of her true hand preference. This means that although better, this sampling is not selective enough to give a perfect fit to the experimental, real pattern. In summary, analysing five flakes may lead to a false positive result.

Figure 6

However, given that few flakes make up most of the archaeological samples (Figure 3 and 4) we decided to perform a series of new simulations involving downscaled experimental samples, instead of removing archaeological groups from the analysis. As Table 1 shows, the number of flakes per group from the experimental sample ranged between 47 and 140 flakes. Consequently, we downscaled each experimental group of refits to fewer flakes per knapper. This simulation was made by taking the median of each variable, preserving the weight of each technical feature from the original distribution pattern. We reduced the experimental sample to five flakes (Figure 7a), six flakes (Figure 7b), seven flakes (Figure 7c), and eight flakes per knapper (Figure 7d), the last group showing the same pattern between the downscaled experimental subsamples and the original experimental sample group. Therefore, eight is the minimum number of flakes required to identify the hand laterality of a knapper above a confidence level of $93.75 \%$.

These simulations allowed us to obtain the confidence rate for each downscaling of the experimental sample. As Figure 7a shows, the distribution pattern of the downscaled experimental subsample is quite similar to the pattern of the original experimental 
sample (Figure 2). An analysis of 5 five flakes entails only a $73.33 \%$ probability of correctly targeting the hand laterality of the knapper, since groups of five flakes fail to achieve their correct position in the plot: individuals L_Et, L_4, L_3, R_4 and R_3 are positioned outside the sector of their true hand preference, when analysing just 5 five flakes. Actually, these individuals are showing false positives. Besides, the margin of success is greater for the right-handed population (75\%), than for the left-handed population $(71.42 \%)$.

By analysing 6 six flakes (Figure $7 \mathrm{~b}$ ) we still have some individuals that are positioned outside the sector of their true hand preference. These individuals are R-Mn, L_1, L-2, L-3, L-4. Interestingly, by analysing six flakes (Figure 7b) the probability of correctly identifying the hand preference of the sample reduces to $66.66 \%$, even though with this number the probability of correctly assigning right-handers is higher $(87.5 \%$, with lefthanders being only $42.85 \%$ ). Nevertheless, by analysing seven flakes the improvement in the results is notable, since the probability of targeting the hand preference of the knapper rises to $93.33 \%$ (Figure $7 \mathrm{c}$ ). In this case, only one group of flakes (L_3) belonging to a left-handed knapper is wrongly positioned as a right-handed individual. Therefore, the margin of error, the probability of a false positive has decreased to $6.66 \%$. Finally, analysing eight flakes per knapper guarantees the correct distribution of the experimental population with regard to their hand preference (Figure 7d), above a confidence level of $93.75 \%$.

Figure 7 
With this information, we looked once again at the archaeological sample group using refits formed by eight or more flakes. Only five groups of refits fulfil this condition, all from the Abric Romaní site: one from level Ja (sample AR1), and 4 four from level M (samples AR5; AR6; AR7; AR8). Figure 8 shows the distribution of these samples, where all the archaeological groups fit the right-handed pattern of knappers, similar to that of the experimental participant R_A_B. However, experimental right-handed knapper R_Nu appears in the area of left-handed knappers, showing a false positive. This false positive means that there is still a small margin of error $(6.66 \%)$. This fact particularly affects the archaeological group of refits AR5, nearest the $\mathrm{X}$ axis, which varies its position depending on whether the experimental knapper R_Nu is included in (Figure 8), or excluded from (Figure 9) the analysis. In the first case, AR5 appears as a right-handed knapper; in the second case, she is left-handed.

Figure 8

Figure 9

In summary, right-handed Neanderthals knapped four of the five groups of flakes detached at Abric Romaní with about 94\% level of certainty, while one remains difficult to assign to a group. In Gran Dolina-TD10-1, only one group of flakes (GR29) contains enough information to be $73.33 \%$ certain that they were produced by a right-handed knapper.

\section{Discussion}


The aim of this paper is to apply a method to the archaeological record that allows us to identify the hand laterality of our ancestors, and discern when and how this feature, which is most prominent in humans, appeared in our evolutionary history. The importance of this issue lies in the organisation of the brain, where our motor, sensory and cognitive functions are structured accord with this laterality.

Previous approaches to the hand laterality of our ancestors have mainly involved the hominin remains found at certain sites. However, these remains are scarce and do not always include the body parts that provide information on this question. Other approaches using stone tools, such as use-wear analysis, have been successful, but require the tools to have been both used sufficiently and be well preserved. Other proxies drawn from the study of single technological features of flakes (i.e., Toth, 1985; Rugg and Mullane, 2001; Domínguez-Ballesteros and Arrizabalaga, 2015) have been questioned from the beginning by authors such as Patterson and Sollberger (1986), Pobiner (1999), and Bargalló and Mosquera (2014). These papers discuss the reliability of finding out the hand preference of one individual by using only one technical feature.

The study presented here applies a previously published method (Bargalló and Mosquera, 2014), which deals with handedness in human evolution by analysing a combination of certain technical features of the most widely-produced stone tools in the Pleistocene world: flakes. We used a multivariate statistical analysis (Correspondence analysis), since alternative classification methodologies (i.e., Binary Logistic Regression and applied a simple Machine Learning algorithm) could not significantly outperform the null model (i.e., random laterality attribution). 
The selected method requires flakes produced by the same knapper, meaning that these flakes must be identified from the archaeological assemblage. It is quite difficult to isolate an individual knapping event in an archaeological assemblage, given that most archaeological levels are actually palimpsests. Preliminary archaeostratigraphic approaches to isolating the remains of each living floor, and a subsequent search for refits, are required to identify singular events (Lucas, 2005; Bailey, 2007; Bargalló et al., 2015; Machado et al., 2015). Because these singular knapping events may involve more than one core (Vaquero, 2008), it is necessary to identify a unique core and the flakes that refit one another. However, ethnographic records show that different knappers (Stout, 2002; Bril et al., 2005) may have worked on the same core. Nevertheless, the archaeological lithic samples we used in this study have the following characteristics: 1) all the archaeological groups of refits are formed by relatively few pieces, never exceeding forty flakes, and 2) the technical features of the flakes are completely homogeneous within each group of refits, suggesting that they were all produced by the same person.

The matter of how much raw material may condition the analysis has been solved by selecting archaeological refit groups of quartzite for Atapuerca and flint from Abric Romaní. Both rock types were frequently used in prehistory, as well as at each of these sites, and they are good quality materials, retaining the maximum number of technical features produced by the knapping process, unlike quartz, where the large crystal structures makes it difficult to preserve many striking platforms (de Lombera-Hermida, 2009). 
In addition, this paper also highlights other potential uses of refit studies. Until now, they have been used to analyse the spatial distribution of remains within occupations; to understand the way the tools were produced; to identify how hominins organised the tasks performed inside the settlements; and to identify the movements of the individuals within these activity areas (Cahen et al., 1979; Hofman, 1981; Bodu et al., 1990; Ashton, 2004; Turq et al., 2013). Now, refits can also be used to facilitate the identification of individuals and provide an understanding of their technological cognition.

In this sense, studying the handedness of the fossil hominins is not mere "storytelling", providing anecdotal information, but the information may help us understand the development of the complex brain organisation during human evolution, and to discover how individuals engaged within their communities. In the words of Foulds: "...this is a

reference to an individual agent within a wider society founded on the social relationships that they both create and maintain, irrespective of how they conceived of themselves" (Foulds, 2014: 13).

\section{Conclusions}

The minimum number of flakes necessary to successfully identify hand laterality at about $94 \%$ of confidence is eight. They must be produced by the same knapper, and the only way to ensure this from the archaeological record is to find eight flakes that refit one other because they were produced from a single core-knapping event. In addition, 
there is no single technical feature that provides information about hand preference, but instead there is a combination of eight technical features, located on the striking platforms and the ventral surfaces. Raw material is not relevant in the case of the mostwidely used rocks in Europe, flint and quartzite, since the majority retain the technical features required for analysis. The exception to this is quartz, where many flakes from the striking platform are lost during the percussion. Expertise is not an issue either, since the technical features analysed here correlate only with handedness, and not the technical quality of the tools (Bargalló and Mosquera, 2014).

Our results indicate that just one pre-Neanderthal knapper from TD10.1 at Gran Dolina (Atapuerca) may be suitable for analysis, since only one refit group containing 5 five quartzite flakes was found. It has been ascertained with a $73.3 \%$ confidence rate that this individual was right-handed. The Abric Romaní Neanderthal knappers provide us with better results. Levels Ja and M yielded five refit groups made up of more than eight flakes, allowing us to clearly distinguish the presence of four right-handers, with the hand preference of one remaining unclear.

Even though eight flakes is a relatively low figure, this number is still quite difficult to obtain at many archaeological sites. This is the case of Gran Dolina-TD10.1, which up to now has yielded 29 groups of quartzite refits from knapping sequences, none of which exceeds 5 five flakes. Nevertheless, these figures may increase in the near future, and more success may be seen when applying the method to the Neogene chert assemblage, which is much more numerous, but also much more difficult to refit, due to the poor preservation of this rock type. 
The possibility of identifying the handedness of our ancestors, in this case from $300 \mathrm{ka}$ and $50 \mathrm{ka}$ ago at Gran Dolina-TD10.1 and Abric Romaní, respectively, signifies a big step forward in the field of human evolution, no matter the age of the samples. Further study should eventually allow us to fix the time when handedness arose and, by extension, know at what point brain laterality developed in humans at both the individual and population levels, as well as which hominin species were partially or totally lateralised. It is possible that our earliest ancestors started to display handedness, but perhaps more sporadically, as seen in living chimpanzee populations. We will also be able to understand the progression of this cognitive feature through our phylogeny, and whether it was a progressive change or one that appeared suddenly. In addition, we will be able to study the role that social and cultural environments may have played in the evolution of this characteristic. Our method ensures this goal through studying the knapping activities of our ancestors, one of the best-recorded tasks with well-preserved remains.

\section{Acknowledgments}

The authors would like to thank F. Romagnoli for her comments and suggestions on the first draft. This work has been carried out with the financial support of Spanish Ministerio de Economía y Competitividad projects HAR2012-32548-HIST, and CGL2012-38434-C03-03.AB has been founded from the European Union's Horizon 2020 research and innovation programme under the Marie Sklodowska-Curie Action grant agreement PREKARN $\mathrm{n}^{0}$ 702584. SL is supported by the Ramón y Cajal programme through the grant RYC-2012-01043. The authors are grateful to the 
participants in the experimental tests, and to G. Chacón, F. Romagnoli and M. Vaquero from Abric Romaní, and A. de Lombera-Hermida, and E. López-Ortega, from Gran Dolina, for working on the archaeological refits at the two sites.

\section{References}

Annett, M., 2002. Handedness and Brain Asymmetry: The Right Shift Theory. Psychology Press, Hove.

Arnold, L.J., Demuro, M., In press. Insights into TT-OSL signal stability from singlegrain analyses of known-age deposits at Atapuerca, Spain. Quaternary Geochronology. DOI: 10.1016/j.quageo.2015.02.005.

Arnold, L.J., Demuro, M., Parés, J.M., Pérez-González, A., Arsuaga, J.L., Bermúdez de Castro, J.M., Carbonell, E., 2015. Evaluating the suitability of extended-range luminescence dating techniques over early and Middle Pleistocene timescales: published datasets and case studies from Atapuerca, Spain. Quatern Int. 389, 167-190.

Ashton, N., 2004. The role of refitting in the British Lower Palaeolithic: a time for reflection. In: Walker, E.A., Wenban-Smith, F., Healy, F. (Eds.), Lithics in Action. Oxbow Books, Oxford, pp. 57-64.

Bailey, G., 2007. Time perspectives, palimpsest and the archaeology of time. Journal of Anthropological Archaeology 26, 198-223. 
Bargalló, A. Mosquera, M., 2014. Can hand laterality be identified through lithic technology. Laterality 19, 37-63.

Bargalló, A., Gabucio, M.J., Rivals, F., 2015. Puzzling out a palimpsest: Testing an interdisciplinary study in level O of Abric Romaní, Quatern. Int. 417, 51-65.

Berger, G.W., Pérez-González, A., Carbonell, E., Arsuaga, J.L., Bermúdez de Castro, J.M., Ku, T., 2008. Luminescence chronology of cave sediments at the Atapuerca paleoanthropological site, Spain. Journal of Human Evolution. 55, 300-311.

Bermúdez de Catro, J.M. Bromage, T.G. Fernàndez Jalvo, Y., 1988. Buccal striations on fossil human anterior teeth: Evidence of handedness in the middle and early Upper Pleistocene. Journal of Human Evolution. 17, 403-412.

Bermúdez de Castro, J.M. Martinón-Torres, M. Sarmiento, S. Lozano, M. Arsuaga, J.L. Carbonell, E., 2003. Rates of anterior teeth wear in Middle Pleistocene hominins from Sima de los Huesos (Sierra de Atapuerca, Spain). Proceedings of the National Academy of Sciences, USA 100, 11992-11996

Bischoff, J.L., Julia, R., Mora, R., 1988. Uranium-series dating of the Mousterian occupation at the Abric Romani, Spain. Nature 332, 68-70.

Bleed, P., 2004. Refitting as aggregate analysis. In: Hall, C.T., Larson, M.L. (Eds.), Aggregate Analysis in Chipped Stone. University of Utah Press, Salt Lake City, pp.184198. 
Bodu, P., Karlin, C., Ploux, S., 1990. Who's who? The Magdalenian flintknappers of Pincevent (France), In: Czielsa, E., Eickhoff, S., Arts, N., Winter, E. (Eds.), The Big Puzzle. International Symposium on Refitting Stone Artefacts. Monrepos. Studies in Modern Archaeology, Holos, Bonn, pp.143-163.

Bril, B., Roux, V., Dietrich, G., 2005. Stone knapping: Khambhat (India), a unique opportunity? In: Roux, V., Bril, B. (Eds), Stone Knapping: the Necessary Conditions for a Uniquely Hominin Behaviour. McDonald Institute Monographs, pp. 53-71.

Bromage, T.G., Boyde, A., 1984. Microscopic criteria for the determination of directionality cutmarks on bone. American Journal of Physical Anthropology 65, 359366.

Bromage, T.G. Bermúdez de Castro, J.M. Fernández-Jalvo, Y., 1991. The SEM in taphonomic research and its application to studies of cutmarks generally and the determination of handedness specifically. Anthropologie Brno XXIX, 163-169.

Cahen, D., Keeley, L., Van Noten, F., 1979. Stone tools, toolkits and human behavior in Prehistory. Current Anthropology 20, 661-683.

Carbonell, E., Mosquera, M., Ollé, A., Rodríguez-Álvarez, X.P., Sahnouni, M., Sala, R., Verges, J.M., 2001. Structure morphotechnique de l'industrie lithique du Pléistocéne inférieur et moyen d'Atapuerca (Burgos, Espagne). L'Anthropologie 105, 259-280. 
Carbonell, E. (Ed.), 2012. High Resolution Archaeology and Neanderthal Behaviour. Springer, New York.

Carretero, J.M., Arsuaga, J.L., Lorenzo, C., 1997. Clavicles, scapule and humeri from the Sima de los Huesos site (Sierra de Atapuerca, Spain). Journal of Human Evolution $33,357-408$.

Cooper, J., Qiu, F., 2006. Expediting and standardizing stone artifact refitting using a computerized suitability model. Journal of Archaeological Science 33, 987-998.

Corballis, M.C., 2003. From mouth to hand: Gesture, speech, and the evolution of righthandedness. Behavioral and Brain Sciences 26, 199-260.

Cziesla, E., 1990. On refitting of stone artefacts. In: Cziesla, E., Eickhoff, S., Arts, N., Winter, E. (Eds.), The Big Puzzle. International Symposium on Refitting Stone Artefacts. Holos, Bonn, pp. 9-44.

Cziesla, E., Eickhoff, S., Arts, N., Winter, E. (Eds.), 1990. The Big Puzzle. International Symposium on Refitting Stone Artefacts, Holos, Bonn.

De Lombera-Hermida, A., 2009 The scar identification of lithic quartz industries. In: Sternke, F., Costa, L.J., Eigeland, L. (Eds.), Non-flint Raw Material Use in Prehistory. Old Perjudices and New Direction. Proceedings of the XV World Congress of the UISPP. BAR International Series, Archaeopress, Oxford, pp. 5-11. 
Dominguez-Ballesteros, E., Arrizabalaga, A., 2015. Flint knapping and determination of human handedness. Methodological proposal with quantifiable results. Journal of Archaeological Science: Reports 3, 313-320.

Falguéres, C., Bahain, J.J., Yokoyama, Y., Arsuaga, J.L., Bermúdez de Castro, J.M., Carbonell, E., Bischoff, J.L., Dolo, J.M., 1999. Earliest humans in Europe: the age of TD6 Gran Dolina, Atapuerca, Spain. Journal of Human Evolution 37, 343-352.

Falguères, C., Bahain, J.-J., Bischoff, J.L., Pérez-González, A., Ortega, A.I., Ollè, A., Quiles, A., Ghaleb, B., Moreno, D., Dolo, J.-M., Shao, Q., Vallverdú, J., Carbonell, E., Bermúdez de Castro, J.M., Arsuaga, J.L., 2013. Combined ESR/U-series chronology of Acheulian hominid-bearing layers at Trinchera Galería site, Atapuerca, Spain. Journal of Human Evolution 65, 168-184.

Falk, D., 1987. Brain lateralisation in primates and its evolution in hominids. Yearbook of Physical Anthropology 30, 107-125.

Fiore, I. Bondioli, L. Radovcic, J. Frayer, D.W., 2015. Handedness in the Krapina Neandertals: A re-evaluation. PaleoAnthropology 2015, 19-36.

Foulds, F., 2014. Invisible Individuals, Visible Groups: On the evidence for individuals and groups at the Lower Palaeolithic site of Caddington, Bedfordshire, UK. In: Foulds, F.W.F. Drinkall, H.C. Perri, A.R. Clinnick, D.T.G. Walker, J.W.P. (Eds.) Wild things: recent advances in Palaeolithic and Mesolithic research. Oxford, Oxbow Books, pp. 1240. 
Frayer, D.W., Fiore, I., Lalueza-Fox, C., Radovcic, J., Bondioi, L., 2010. Right handed Neandertals: Vindija and beyond. Journal of Anthropological Sciences 88, 113-127.

Frayer, D.W., Lozano, M., Bermúdez de Castro, J.M., Carbonell, E., Arsuaga, J.L., Radovcic, J., Fiore, I., Bondioli, L., 2012. More than 500,000 years of right-handedness in Euope. Laterality: Asymmetries of Body, Brain and Cognition 17, 51-69.

Gómez de Soler, B., 2007. Áreas de captación y estrategias de aprovisionamiento de rocas silíceas en el nivel L de Abric Romaní (Capellades, Barcelona). M.Sc. Dissertation, Universitat Rovira i Virgili.

Hall, C.T., 2004. Evaluating prehistoric hunter-gatherer mobility, land use, and technological organization strategies using minimum analytical nodule analysis. In: Hall, C.T., Larson, M.L. (Eds.), Aggregate Analysis in Chipped Stone. University of Utah Press, Salt Lake City, pp. 139-155.

Hammer, Ø., Harper, D.A.T., Ryan, P.D., 2001. PAST: Paleontological Statistics Software Package for Education and Data Analysis. Palaeontologia Electronica, 4, 9. http://palaeoelectronica.org/2001_1/past/issue1_01.htm

Hammer, Ø., Harper, D.A.T., Ryan, P.D., 2008. PAST: Palaeontological Statistics, ver. 1.81. http://folk.uio.no/ohammer/past/past.pdf 
Hofman, J., 1981. The refitting of chipped-stone artifacts as an analytical and interpretive tool. Current Anthropology 22 , 691-693.

Holloway, R.L., 1976. Palaeoneurological evidence for language origins. In: Harnad, S.R., Steklis, H.D., Lancaster, J. (Eds.) Origins and Evolution of Language and Speech. New York Academy of Sciences, New York, pp. 330-348

Hopkins, W.D., 1996. Chimpanzee handedness revisited: 55 years since Finch Psuchonomic Bulletin and Review 3, 449-457.

Hopkins, W.D., Cantalupo, C., 2005. Individual and setting differences in the hand preferences of chimpanzees (Pan troglodytes): A critical analysis and some alternative explanations. Laterality: Asymmetries of Body, Brain and Cognition 10 , 65-80.

Hopkins, W.D., Wesley, M.J., Izard, M.K., Hook, M., Schapiro, M.J., 2004. Chimpanzees (Pan troglodytes) are predominantly right-handed: replication in three populations of apes. Behavioral Neuroscience 118, 659-663.

Knecht, S., Dräger, B., Deppe, M., Bobe, L., Lohman, H., Flöel, A., Ringelstein, E.-B., Henningsen, H., 2000. Handedness and hemispheric language dominance in healty humans. Brain 123, 2512-2518.

Lazenby, R.A., 2002. Skeletal biology, functional asymmetry and the origins of 'handedness'. Journal of Theoretical Biology 218, 129-138. 
Llorente, M., 2011. Lateralidad manual y especialización hemisférica en chimpancés (Pan troglodytes). Evaluación experimental y obervacional. Ph.D. Dissertation, Universitat Ramon Llull.

Llorente, M., Mosquera, M., Fabré, M., 2009. Manual laterality for simple reaching and bimanual coordinated task in naturalistic housed Pan troglodytes. International Journal of Primatology 30 , 183-197.

Llorente, M., Riba, D., Palou, L., Carrasco, L., Mosquera, M., Colell, M., Feliu, O., 2011. Population-level right-handedness for a coordinated bimanual task in naturalistic housed chimpanzees: replication and extension in 114 animals from Zambia and Spain. American Journal of Primatology 73, 281-290.

Larson, M.L., 2004. Chipped stone aggregate analysis in archaeoloegy. In: Hall, C.T., Larson, M.L. (Eds.), Aggregate Analysis in Chipped Stone. University of Utah Press, Salt Lake City, pp. 3-17.

López-Ortega, E., Bargalló, A., de Lombera-Hermida, A., Mosquera, M., Ollé, A., Rodríguez-Álvarez, X.P., In press. Quartz and quartzite refits at Gran Dolina (Sierra de Atapuerca, Burgos): Connecting lithic artefacts in the Middle Pleistocene unit of TD10.1. Quaternary International DOI:10.1016/j.quaint.2015.09.026.

Lozano, M. Mosquera, M. Bermúdez de Castro, J.M. Arsuaga, J.L. Carbonell, E., 2009. Right handedness of Homo heidelbergensis from Sima de los Huesos Atapuerca, Spain 500,000 years ago. Evolution and Human Behavior 30, 369-376. 
Lucas, G., 2005. The Arcaheology of Time. Routledge, London.

Machado, J., Mallol, C., Hernández, C.M., 2015. Insights into Eurasian Middle Paleolithic settlement dynamics: the palimpsest problem. In: Conard, N.J., Delagnes, A. (Eds.), Settlement Dynamics of the Middle Paleolithic and Middle Stone Age, vol IV. Kerns Verlag, Tübingen, pp. 361-382.

McGrew, W.C., Marchant, L.F., 1997. On the other hand: Current issues in and metanalysis of the behavioural laterality of hand function in nonhuman primates. Yearbook of Physical Anthropology 40, 201-232.

McGrew, W.C., Marchant, L.F., 2001. Ethological study of manual laterality in the chimpanzees of the Mahale mountains, Tanzania. Behavioural Processes 138, 329-358.

McPherron, S.P., Alemseged, Z., Marean, C.W., Wynn, J.G., Reed, D., Geraads, D., Bobe, R., Bearat, H.A., 2010. Evidence for stone-tool-assisted consumption of animal tissues before 3.39 million years ago at Dikika, Ethiopia. Nature 466, 857-860.

Moreno, D., Falguères, C., Pérez-González, A., Voinchet, P., Ghaleb, B., Despriée, J., Bahain, J.J., Sala, R., Carbonell, E., Bermúdez de Castro, J.M., Arsuaga, J.L., In press. New radiometric dates on the lowest stratigraphical section (829 TD1 to TD6) of Gran Dolina site (Atapuerca, Spain). Quaternary Geochronology. DOI:10.1016/j.quageo.2015.05.007 
Mosquera, M., Llorente, M., Riba, D., Lorenzo, C., Carbonell, E., Feliú, O., 2007. Ethological study of manual laterality in naturalistic housed chimpanzees (Pan troglodytes) from the Mona Foundation Sanctuary (Girona, Spain). Laterality: Asymmetries of Body, Brain and Cognition $12,19-30$.

Mosquera, M., Geribàs, N., Bargalló, A., Llorente, M., Riba, D., 2012. Complex tasks force hand laterality and technological behaviour in naturalistically housed chimpanzees: inferences in hominin evolution. The Scientific World Journal 2012. DOI:10.1100/2012/514809.

Odell, G.H., 2004. Lithic Analysis. Kluwer Academic/Plenum Publishers, New York.

Ollé, A., 2003. Variabilitat I patrons funcionals en els Sistemes Tècnics de Mode 2. Anàlisi de les deformacions d'ús en els conjunts lítics del Riparo Estreno de Grotta Paglicci (Rignamo Garganico, Foggia), Áridos (Arganda, Madrid) i Gatería-TN (Sierra de Atapuerca, Burgos). Ph.D. Dissertation, Universitat Rovira i Virgili.

Ollé, A., Mosquera, M., Rodríguez-Álvarez, X.P., de Lombera-Hermida, A., GarcíaAntón, M.D., García-Medrano, P., Peña, L., Menéndez, L., Navazo, M., Terradillos, M., Bargalló, A., Márquez, B., Sala, R., Carbonell, E., 2013. The Early and Middle Pleistocene technological record from Sierra de Atapuerca (Burgos, Spain). Quaternary International 295, 138-167.

Patterson, L.W., Sollberger, J.B., 1986. Comments on Toth's right-handedness study. Lithic Technology 15, 109-111. 
Pickering, T.R., Hensley-Marschand, B., 2008. Cutmarks and hominid handedness. Journal of Archaeological Science 35, 310-315.

Pobiner, B.L., 1999. The use of stone tools to determine handedness in hominids. Current Anthropology 40, 90-92.

Poza-Rey, E.M., Lozano, M., Arsuaga, J.M., 2017. Brain asymmetries and handedness in the specimens from the Sima de los Huesos site (Atapuerca, Spain). Quaternary International 433, 32-44

Rodríguez, J., Burjachs, F., Cuenca-Bescós, G., García, N., Van der Made, J., PérezGonzález, A., Blain, H.A., Expósito, I., López-García, J.M., García-Anton, M., Allué, E., Cáceres, I., Huguet, R., Mosquera, M., Ollé, A., Rosell, J., Parés, J.M., RodríguezÁlvarez, X.P., Díez, J.C., Rofes, J., Sala, R., Saladié, P., Vallverdú, J., Bennasar, L., Blasco, R., Bermúdez de Castro, J.M., Carbonell, E., 2011. One millions years of cultural evolution in a stable environment at Atapuerca (Burgos, Spain). Quaternary Science Reviews 30, 1396-1412.

Rodríguez-Álvarez, X.P., 1997. Sistemas técnicos de producción lítica del Pleistoceno Inferior y Medio en la Península Ibérica: variabilidad tecnológica entre yacimientos del Noreste y de la Sierra de Atapuerca. Ph.D. Dissertation, Universitat Rovira i Virgili.

Rodríguez-Álvarez, X.P., 2004. Technical Systems of Lithic Production in the Lower and Middle Pleistocene of the Iberian Peninsula: Technological Variability between 
North-Eastern Sites and Sierra de Atapuerca Sites., BAR International Series S1323. Archaeopress, Oxford.

Roebroeks, W., 1988. From Find Scatters to Early Hominid Behavior: a Study of Middle Palaeolithic Riverside Settlements at Maastricht-belvedere (The Netherlands). Analecta Praehistorica Leidensia 25, 1-16.

Rugg, G., Mullane, M., 2001. Inferring handedness from lithic evidence. Laterality: Asymmetries of Body, Brain and Cognition 6, 247-259.

Schäfer, J., 1990. Conjoining of artefacts and consideration of raw-material: their application at the Middle Palaeolithic site of the Schweinskopf-Karmelenberg. In: Cziesla, E., Eickhoff, S., Arts, N., Winter, E. (Eds.), The Big Puzzle. International Symposium on Refitting Stone Artefacts. Holos, Bonn, pp. 83-100.

Schick, K., Toth, N., 2009. African origin. In: Scarre, C. (Ed.),The Human Past: World Prehistory and the Development d Human Societies. Thames \& Hudson, Portland, Ore, USA, pp 46-83.

Shaw, C.N., 2011. Is "hand preference" coded in the hominin skeleton? An in-vivo study of bilateral morphological variation. Journal of Human Evolution 61, 480-487.

Soto, M., Gómez de Soler, B., Vallverdú, J., Vaquero, M., 2014. Potential siliceous sources during prehistory: Results of prospecting in the east margin of the Ebro Basin (NE Iberian Peninsula). Journal of Lithic Studies 1, 293-318. 
Stout, D., 2002 Skill and cognition in stone tool production. Current Anthropology 43, $693-722$

Teixeira, L.A., Okazaki, V.H.A., 2007. Shift of manual preference by lateralized practice generalizes to related motor tasks. Experimental Brain Research 183, 417-423.

Toth, N., 1985. Archaeological evidence for preferential right handedness in the lower and middle Pleistocene and its possible implications Journal of Human Evolution 14, 607-614.

Turq, A., Roebroeks, W., Bourguignon, L., Faivre, J.P., 2013. The fragmented character of Middle Palaeolithic stone tool technology. Journal of Human Evolution 65, 641-655.

Uomini, N.T., 2009. The prehistory of handedness: Archaeological data and comparative ethology. Journal of Human Evolution 57, 411-419.

Vallverdu, J., Gomez de Soler, B., Vaquero, M., Bischoff, J. L., (2012). The Abric Romani site and the Capellades region. In: Carbonell, E. (Ed.), High Resolution Archaeology and Neandertal Behavior: Time and Space in Level $\mathbf{J}$ of Abric Romaní (Capellades, Spain). Vertebrate Paleobiology and Paleoanthropology. Springer, New York. pp. 19-46. 
Vaquero, M., 2008. The history of stones: behavioural inferences and temporal resolution of an archaeological assemblage from the Middle Palaeolithic. Journal of Archaeological Science 35, 3178-3185.

Vaquero, M., Chacón, M.G., García-Antón, M.D., Gómez de Soler, B., Martínez, K., Cuartero, F., 2012. Time and space in the formation of lithic assemblages: The example of Abric Romaní Level J. Quaternary International 247, 162-181.

Vaquero, M., Pastó, I., 2001. The definition of spatial units in middle Palaeolithic sites: the hearth-related assemblages. Journal of Archaeological Science 28, 1209-1220.

Vaquero, M., Allué, E., Bischoff, J.L., Burjachs, F., Vallverdú, J., 2013. Environmental, depositional and cultural changes in the Upper Pleistocene and Early Holocene: the Cinglera del Capelló sequence (Capellades, Spain). Quaternaire 24, 49-64.

\section{Figure legends}

Figure 1: Technical features analysed. Top: technical features present on the flakes. Bottom: possible locations of the ridge of the bulb, the éraillure scars, hackles, ripples, inclination of the extraction axis, inclination of the striking platform and the type of striking platform. 
Figure 2: Correspondence analysis of the experimental sample: left-handed knappers (L$\mathrm{x})$ are located above factor 2, while right-handed knappers (R-x) are located below this. All the samples are represented by triangles.

Figure 3: Left: Complete and broken flakes belonging to 34 groups of refits found from in level TD10.1 at the Gran Dolina site (Sierra de Atapuerca, Spain). Right: Archaeological refit groups GD8 and GD2 (photographs from López-Ortega, 2015).

Figure 4: Top: Complete and broken flakes belonging to eight groups of refits selected from levels Ja and M from the Abric Romaní Neanderthal site (Barcelona, Spain). Bottom: Archaeological refit groups AR1 (photograph from Vaquero et al., 2012) and AR8 (photograph by F. Romagnoli).

Figure 5: Correspondence analysis of the entire set of experimental and archaeological samples. Triangles: experimental refit groups. + : refit groups from TD10.1, Gran Dolina $(G D)$. Circles: refit groups from levels Ja and M, Abric Romaní $(A R)$. (Axis 1= $19.7 \%$ eigenvalue; Axis $2=16.86 \%$ eigenvalue). The two axes represent $36.56 \%$ of the total.

Figure 6: Correspondence analysis of the experimental and archaeological samples, selecting just the archaeological refit groups with five or more flakes. Triangles: experimental refit groups. +: the only refit group from TD10.1 (GD29) with five flakes. Circles: the eight refit groups from Abric Romaní $(A R)$ with five or more flakes (Axis $1=28.36 \%$ eigenvalue; Axis $2=18.63 \%$ eigenvalue). The two axes represent $46.99 \%$ of 
the total. Shadowed individual (R_Nu) is positioned outside the sector of her real hand preference.

Figure 7. Correspondence analysis of the experimental sample downscaled to " $n$ " flakes per knapper. Triangles: right-handed knappers, both for the original experimental sample (R_"x") and the subsample downscaled to "n" flakes (R_"n"). +: left-handed knappers, both for the original experimental sample (L_" $\mathrm{L}_{\text {") }}$ ) and the subsample downscaled to " $n$ " flakes (L_"n"). 7a. Downscaling the experimental subsample to five flakes (Axis $1=28.49 \%$ eigenvalue; Axis $2=18.53 \%$ eigenvalue). The two axes represent $47.02 \%$ of the total. $7 \mathbf{b}$. Downscaling the experimental subsample to six flakes (Axis $1=28.56 \%$ eigenvalue; Axis $2=17.11 \%$ eigenvalue). The two axes represent $45.66 \%$ of the total. 7c. Downscaling the experimental subsample to seven flakes (Axis $1=28.49 \%$ eigenvalue; Axis $2=15.83 \%$ eigenvalue). The two axes represent $45.66 \%$ of the total. 7d. Downscaling the experimental subsample to eight flakes (Axis $1=26.65 \%$ eigenvalue; Axis $2=17.76 \%$ eigenvalue). The two axes represent $44.41 \%$ of the total. Shadowed samples are outside their real handedness position.

Figure 8: Correspondence analysis. Triangles: experimental subsample downscaled to eight flakes. Circles: the only five archaeological refit groups with eight or more flakes, all from the Abric Romaní site. Experimental knapper R_Nu (shadowed) is outside her real hand preference position (Axis $1=30.93 \%$ eigenvalue; Axis $2=17.03 \%$ eigenvalue). The two axes represent $47.96 \%$ of the total. 
Figure 9: Correspondence analysis. Triangles: experimental subsample downscaled to eight flakes, without the knapper R_Nu. Circles: the five archaeological refit groups with eight or more flakes from Abric Romaní. (Axis 1=29.64\% eigenvalue; Axis 2= $18.11 \%$ eigenvalue). The two axes represent $47.75 \%$ of the total.

\section{Table legend}

Table 1: Number of flakes and broken flakes knapped by each participant during the experimental programme.

Table 2: Frequency of the technical features involved in handedness. The table includes the experimental and archaeological samples from Abric Romaní refit groups (AR). R_"x" and L_"x": refit groups of right- and left-handed experimental knappers, respectively.

Table 3: Frequency of the technical features involved in handedness. The table includes the experimental and archaeological samples from Gran Dolina-TD10.1 level (GD). 


\title{
IN PURSUIT OF OUR ANCESTORS HAND LATERALITY
}

| Amèlia Bargalló ${ }^{1}$, Marina Mosquera ${ }^{3,2}$, Sergi Lozano ${ }^{2,3}$

\begin{tabular}{|l}
1 University College London, Institute Archaeology, London, Great Britain. \\
${ }^{2}$ IPHES, Institut Català de Paleoecologia Humana i Evolució Social, Tarragona, Spain \\
${ }^{3}$ Area de Prehistoria, Universitat Rovira i Virgili (URV), Tarragona, Spain
\end{tabular}

Corresponding author: ameliabarg@gmail.com

\begin{abstract}
The aim of this paper is to apply a previously published method (Bargalló and Mosquera $_{2} 2014$ ) to the archaeological record, allowing us to identify the hand laterality of our ancestors and determine when and how this feature, which is exhibited most strongly in humans, appeared in our evolutionary history. The method focuses on identifying handedness by looking at the technical features of the flakes produced by a single knapper, and discovering how many flakes are required to ascertain their hand preference.
\end{abstract} Formatted: Line spacing: Double

This method can potentially be applied to the majority of archaeological sites, since flakes are the most abundant stone tools, and stone tools are the most widespread and widely-preserved remains from prehistory. For our study, we selected two Spanish sites: Gran Dolina-TD10.1 (Atapuerca) and Abric Romaní (Barcelona), which were occupied by pre-Neanderthal and Neanderthal populations, respectively.

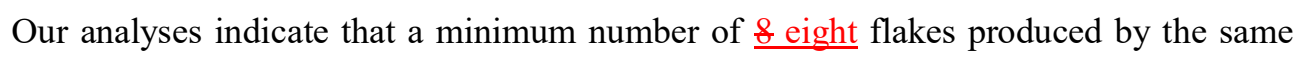
knapper is required to ascertain their hand preference. Even though this figure is relatively low, it is quite difficult to obtain from many archaeological sites. In addition, there is no single technical feature that provides information about handedness, instead 
there is a combination of \&-eight technical features, localised on the striking platforms and ventral surfaces. The raw material is not relevant where good quality rocks are used, in this case quartzite and flint, since most of them retain the technical features required for the analysis. Expertise is not an issue either, since the technical features analysed here only correlate with handedness (Bargalló and Mosquera, 2014). Our results allow us to tentatively identify one right-handed knapper among the pre-Neanderthals of level TD10.1 at Gran Dolina (Atapuerca), while four of the five Neanderthals analysed from Abric Romaní were right-handed. The hand preference of the fifth knapper from that location (AR5) remains unclear.

Keywords: Hand laterality, flakes, lithic technology, Atapuerca, Abric Romaní

\section{Introduction}

Laterality is the preference that living beings display for one half of the body over the other. This organisation settles in the structure of the brain, the organ that designates the role played by each extremity when performing a task.

Hand laterality is well known in our species, Homo sapiens-sapiens.sapiens Various studies point to about $97 \%$ of the current population being lateralised, among which between $85 \%$ and $90 \%$ of individuals are right-handed, and between $10 \%$ and $15 \%$ are left-handed, depending on whether the communities are preindustrial, illiterate, and so on (Annett, 2002; Uomini, 2009). Hand laterality in apes has also been studied (Hopkins, 1996; McGrew and Marchant, 1997, 2001; Hopkins and Cantalupo, 2005), 
but it is less marked than human handedness and depends on several environmental and social conditions (Mosquera et al., 2007; Llorente et al., 2009, 2011). According to Llorente and colleagues: "...there must have been continuity in the evolution of handedness, at least between apes (chimpanzees) and the hominin family" (2011:569. Translated by us). However, the subject is not as straightforward as simply being rightor left-handed, since some studies have highlighted the fact that chimpanzees become more and more lateralised as the task to be done becomes increasingly complex. This condition also leads to an increase $\underline{\text { ff }} \underline{\text { in }}$ their technological behaviour, which has been interpreted as a landmark in the evolution of our hominin clade (Mosquera et al., 2012).

In fact, some researchers support that the most widespread tasks undertaken by humans are those where both hands play different roles: e.g., cutting, where one hand holds the matter to be cut, and the other uses the knife to do the actual cutting. In addition, cutting is not usually needed in the world of apes (Schick and Toth, 2009), which may have marked a strong difference between their ancestors and hominins. These type of tasks are also known as bimanual complementary tasks (McGrew and Marchant, 1999), bimanual complex tasks (Hopkins et al., 2004), and complementary role differentiation tasks (Uomini, 2009), which are indeed the most complex, as well as the most

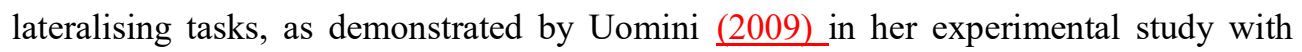
humans (Uomini, 2009). This point of view-interpretation has led to the view that there is a feedback mechanism in the origin of handedness, where the recurring use of one hand gives it more skills compared with the other, in turn favouring the preferential use of the "skilled" hand. Both skill and practice reinforce handedness, a trait that may have favoured brain lateralisation (Teixeira and Okazaki, 2007). From a phylogenetic point of view, hand laterality may have been on the increase since the earliest hominins, as far 
back as Australopithecus (Mosquera et al., 2012). In this sense, cut-marks found at Dikika (Ethiopia) from 3.3 my ago (McPherron et al., 2010) do not inform us about hand laterality, but they are by-products of bimanual complementary tasks (i.e.. cutting, defleshing), which reinforce our hypothesis.

The issue then, is to ascertain when handedness evolved in our hominin clade. Previous approaches to the question of hand laterality in our ancestors mostly focused on the hominin remains recorded from certain sites. Such is the case of in the dental-wear studies $\underline{\text { ffwith }}$ the so-called use of the third hand ("stuff and cut") in some of the preNeanderthal individuals deposited at the Sima de los Huesos site (Atapuerca, Spain) (Bermúdez et al., 1988 2003; Lozano et al., 2009). Other studies have centred on the endocrania (Poza-Rey, 2015), humerus and other limb bones (:Carretero, et al., 1997; Lazenby, 2002; Shaw, 2011). All these studies point to a similar handedness in Neanderthals as is found in modern humans (Frayer et al., 2010; Fiore et al., 2015). For its part, the pre-Neanderthal population of Sima de los Huesos (until recently, Homo heidelbergensis) from 450,000 years ago, is under debate: some researchers find

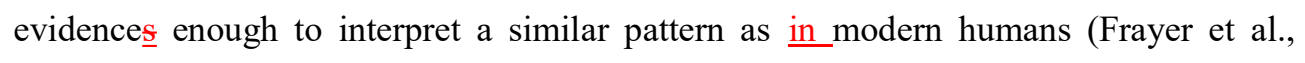
2012), and others find noł well-defined brain lateralization (Poza-Rey et al., 2015).

In fact, the relation between brain asymmetry and hand laterality is not definite definitively solved (see Poza-Rey et al., 2015 for debate), and even just at the paleoanthropological level we may obtain divergent results. As mentioned, several studies pointed out that hand laterality (right-handedness) of Sima de los Huesos hominins may be identified in five 5 individuals by means of labial striations of the frontal dentition (Bermúdez et al., 1988; 2003; Lozano et al., 2009). However, in their 
recent publication on skulls from Sima de los Huesos (Atapuerca, Spain), Poza-Rey and colleagues (2015) have erossed-compared these data with the brain endocasts asymmetries found at in 4four of the skulls to which some of that dentition belongs te: Ecrania/endocrania 16, 10, 9 and 6. Individual 16 and 6 not show a right-handed manual preference in their endocasts asymmetries, but individual 16 shows dental striations to the left, while individual 6 shows the dental striations to the right. Individuals 10 and 9 resulted in-demonstarated right-handed manual preferences in their endocasts asymmetires asymmetries, both associated with tental striations to the right. The authors suggest that the discrepancy obtained in individual 6 may be the result fruit of ambidextrous handedness, but also a product of learning by imitation (Poza Rey et al., 2015: 11).

Anyway, hominin remains are scarce in the archaeological record, and they do not always include the body parts that give us information on this matter. Tests have been carried out on the direction and trajectory of the cut-marks accidentally left on bone surfaces by the stone tools used by hominins when processing prey for consumption (Bromage and Boyde, 1984; Bromage et al., 1991;). However, the results of this method have been also contested (Pickering et al., 2008).

Furthermore, f For this study we have used the only remains that appear commonly at the majority of Pleistocene archaeological sites: stone tools. Because they are the most abundant remains at this these of sites, they can be an excellent source of information. 
One approach that uses stone tools is use-wear analyses, the study of the use-wear developed along the edges of stone tools during use. Use-wear studies have revealed that one of the pre-Neanderthals that used tools to cut the meat off a carcass at the Middle Pleistocene Acheulean site of Galería (Atapuerca, Spain) was right-handed (Ollé, 2003). This type of study can be successful in identifying the hand preference of the user, but the approach requires that the tools themselves were both sufficiently used and well preserved.

Determining hand laterality through the technical study of flakes has been approached from two different perspectives: the knapping method used to produce the flakes (Toth, 1985), and the analyses of one a single technical feature (Rugg and Mullane, 2001; Domínguez-Ballesteros and Arrizabalaga, 2015). Both of these approaches have been discussed and their results questioned because of the methods used (see Patterson and Sollberger, 1986, and Pobiner, 1999 for Toth ${ }_{2}$ 1985, and Bargalló and Mosquera 2014 for Rugg and Mullane, 2001).

Comment [A3]: $\iota$ check and correct Comment [A4]: Ok I checked and corrected.

In this paper, we apply the method we previously published, on how to identify handedness through the technical features of the flakes obtained by a knapper (Bargalló and Mosquera 2 2014), to the archaeological record, with the aim of finding out how many flakes produced by a single Pleistocene knapper are needed for the analysis to ascertain his/her hand preference. As mentioned previously, the benefit of this method is that it can potentially be applied to the majority of archaeological sites.

To do this, we selected two Spanish sites: Gran Dolina-TD10.1 (Atapuerca) and Abric Romaní (Barcelona), which were occupied by pre-Neanderthal and Neanderthal 
populations, respectively. In both species, the handedness of some individuals has been identified, so this study serves to both confirm the previous results and to test the reliability of this method when applied to older sites and hominin species, until the first hominin species that was completely lateralised is found, as well as any evolution in that process. Furthermore, given that the TD10-1 archaeological record was made by pre-Neanderthal populations peri-contemporary to that of SH, our results may come to provide more evidences to-on the current debate.

\section{Method}

In Bargalló and Mosquera (2014) we presented a new method for inferring handedness from lithic evidence. The study was conducted by means of an experimental programme in stone knapping, after which the resulting lithic flakes were analysed. These flakes

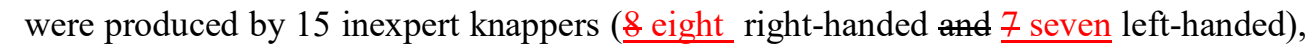
because we were not able to find a statistically significant number of left-handed expert knappers. We considered inexpert knappers to include individuals who had never struck two pebbles together, as well as individuals who were quite familiar with prehistoric tools and had had some degree of practice. Importantly, the Mann-Whitney U test proved that all of them produced flakes with the same technical features concerning handedness, meaning that, within this sample group, expertise was not a factor that affected the presence or absence of these technical features analysed to determine hand laterality. On the contrary, expertise clearly affects the quality of the flakes in technological terms (i.e., longer, sharper edges, regular morphologies, etc.). The results of the experiment indicate that no single variable can be used to determine the laterality 
of the knapper, but instead this requires a combination of several variables. Furthermore, not all flakes display the entire set of significant features. The conclusion of this study is, therefore, that it is not possible to determine the hand preference of a knapper through a single variable present on their flakes, but it may be possible to determine his or her laterality by examining a combination of technical variables on a number of their pieces.

Experimental sample

The experimental sample corresponds to that published in-by Bargalló and Mosquera

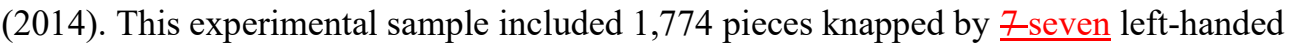
and $\underline{8 \text {-eight }}$ right-handed individuals. Of these, 1,159 were flakes and broken flakes, and 615 were fragments of flake and angular knapping fragments. These latter were not analysed, since they did not retain the necessary technological features. Of the 1,159 flakes and broken flakes, $629(54.23 \%)$ were produced by right-handers and 530 (45.76\%) by left-handers. The knapper who produced the fewest flakes made 49 pieces, and the knapper who generated the most flakes made 140 (Table 1). All the flakes were created from the same type of flint as used by Heme. neandertalensis at the Abric Romaní site (Barcelona, Spain) (Gómez de Soler, 2007; Carbonell, 2012; Soto et al., 2014).

Table 1

Handedness analysis 
According to Bargalló and Mosquera (2014), only \&eight technical features from the complete catalogue of characteristics are informative to ascertain the hand laterality of the knapper. However, given that many pieces do not show the eight technical features indicative of hand preference, and also that the technical characteristics of a single piece may be the fruit-result of chance, a number of flakes knapped by the same individual must be analysed (Figure 1).

Figure 1

The following are the $\underline{\& \text { eight }}$ technical features and their variables $(n=21)$ that provide Comment [A7]: Morphology is spe incorrectly in this figure and there is a accent missing on éraillure in the ventral surface diagram

information about handedness:

a) Ventral surface:

1. Location of the ridge on the bulb, recorded by Rugg and Mullane (2001) as "skew". This small ridge starts at the impact point and runs along the cone of percussion, the proximal part of the whole bulb. It may be located to the right or left.

2. Location of the éraillure scars on the cone. These are small squamae that Formatted: Font: Not Italic sometimes accidentally appear in the bulb. If present, they may be centred, or located to the right or left.

3. Location of the hackles. Small hackles may appear near the edges of the ventral surface. They may be distal, right or left located.

4. Location of the ripples. Long curved wrinkles that appear along the ventral surface and follow the detaching axis of the flake. They may be located distally, or to the right or left.

5. Orientation of the extracting axis of the flake. This may be right or left-oriented 
b) Striking platform:

1. Location of the impact point on the striking platform. This may be right or left located.

2. Inclination of the striking platform. It may be to the right, left, or sinuous

3. Morphology of the striking platform. This may be platform (plan), linear (lineal), or punctiform (pointed).

Figure 2

The correspondence analyses performed at Bargalló and Mosquera (2014) (Figure 2) showed that these features clearly allow the right-handed and left-handed knappers from the experiment to be distinguished. The first two factors explain $55.56 \%$ of the variability (factor 1:-36.57\%, factor 2:-18.99\%). In Figure 2 all the left-handed knappers are placed above factor 2, and the right-handed knappers are placed below factor 2. Therefore, left-handed knappers tend to produce ripples (39.39\%), hackles (31.79\%), the ridge of the cone of percussion $(42.41 \%)$, the éraillure scars $(15.67 \%)$, and the impact points $(88.34 \%$ of the total relative inertia) on the left side of the flake. Interestingly they also tend to detach flakes with the striking platform sloped towards the right side of the piece (33.81\% of the total relative inertia). In contrast, right-handed knappers tend to form ripples (36\%), hackles $(29.49 \%)$, the ridge of the cone of percussion (49.59\%), the éraillure scars $(25.78 \%)$, and the impact points $(49.58 \%$ of the total relative inertia) on the right side of the flake. As opposed to left_handers, righthanded knappers tend to detach flakes with the striking platform sloped towards the leftside of the piece ( $45.89 \%$ of the total relative inertia). 
This work is based on the fact that the patterns of the experimental knappers help us identify the handedness of prehistoric knappers, as the archaeological samples are expected to follow the same patterns as the experimental ones (Figure 2).

\section{Refit analysis}

In order to apply this method to the archaeological record, we need to find flakes detached by the same knapper. This can only be achieved by means of searching refits from knapping sequences of cores, which is a rather complicated process in many archaeological deposits. Although refits do not fully guarantee that only one knapper exploited one core, it is the best approach under the circumstances. Therefore, the first step is to search for as many refits as possible in archaeological samples.

In this study, we only analysed archaeological pieces longer than $10 \mathrm{~mm}$. Depending on the type of raw material, the archaeological assemblage needs to be classified into Raw Material Units (RMU; Roebroeks, 1988; Schäfer, 1990; Odell, 2004; Vaquero, 2008) and Minimum Analytical Nodules (MAN) (Bleed, 2004; Hall, 2004; Larson, 2004; Comment [A9]: Might be better to abbreviate as RMUs and MANs and then use as needed - with or without the $s$ throughout.

Comment [A10]: Ok, I did

Odell, 2004; Copper and Qiu, 2006). RMU are the blanks from which one, two or several cores may be exploited by different knappers. For example, these may be big blanks of flint that are fragmented in order to allow the knappers to take a piece and start the process of stone tool production. Archaeologically, we are unlikely to obtain the entire refit of the blank, since they were often large fragments selected, transported, knapped, abandoned, reused, and so on. Only workshops provide the chance of refitting a whole RMU. For their part, the MAN are each of the cores knapped. For example, a 
cobble knapped into a discoid is one MAN, as is each of the flint-knapped fragments from the abovementioned blank. Archaeologically, MAN are easier to complete by refitting than RMU, although the occupational traits of the sites, their post-depositional conditions, as well as the area excavated usually make this task difficult. Although theoretically the distinction between RMU and MAN is clear, archaeologically it is not always easy to determine whether a particular variety of raw material belongs to a RMU or a MAN. Therefore, throughout this work we will use the general term RMU. Both RMU and MAN allow us to identify the single cobbles/blanks from which the flakes were detached, and indeed, the single knapping events. Associating flakes into RMU and MAN is based on the macroscopic features of the artefacts (e.g., grain-size and colour of the cortical and non-cortical surface, internal inclusions such as microfossils, fractures, and veins) (Schäfer, 1990; Roebroeks, 1998; Odell, 2004; Vaquero, 2008).

Once the pieces have been grouped into RMU and/or MAN, the refitting process begins. There are $\underline{z}$ three types of refits: flakes detached in production/knapping sequences (refits sensu stricto), breakages (conjoins), and modifications (small pieces detached Formatted: Font: Not Italic when retouching a flake) (Cziesla, 1990). In this study, only flakes coming from production sequences (refits) have been used, and only those that refit together.

Data analysis

In this study, Wwe applied in this study a multivariate statistical analysis (Correspondence analysis) using the program P PSTast (Paleontological Statistics 
Software) to identify the hand laterality of prehistoric knappers by comparing them with the experimental sample (Hammer, Harper and Ryan, 2001, 2008). Alternative, $\mathrm{m}$ More conventional, classification methodologies were also considered and evaluated using the experimental data. Specifically, we fitted our data with a Binary Logistic Regression and applied a simple Machine Learning algorithm (i.e., k- nearest neighbours). In both cases, the performance of the resulting classifiers could not significantly outperform the null model (i.e., random laterality attribution).

\section{Archaeological Material}

Gran Dolina TD10.1 (Atapuerca, Spain)

Gran Dolina is one of the caves located at Sierra de Atapuerca, in the north of the Iberian Peninsula, near the city of Burgos. It is filled with $18 \mathrm{~m}$ of sediments divided Comment [A12]: Ok, I changed into 11 lithostratigraphic units named TD1 to TD10, from bottom to top, and with a chronology ranging from the Early to Middle Pleistocene (Berger et al., 2008; Falguères et al., 2013; Arnold et al., 2014; Arnold and Demuro, 2015). In this work, we looked at the lithic remains of subunit TD10.1, which has a mean date of $244-337 \pm 29 \mathrm{ka}$ (Falguères et al., 1999, 2013; Berger et al., 2008; Rodríguez et al., 2011),pessibly but may be closer to $350 \mathrm{ka}$ (Moreno et al., in press).

Up to now, TD10.1 has been the richest subunit of not only Gran Dolina, but all the Sierra de Atapuerca sites, both in terms of lithic and faunal remains. The subunit has 
yielded roughly 21,000 lithic artefacts and 48,000 faunal remains, most of them near the north and east sectors of the excavation (Ollé et al., 2013). Fechnologically, t The lithic remains probably represent the local-scale evolution from Mode 2 to Mode 3 technology at Sierra de Atapuerca. While the lithic remains from upper TD10.1 show features typical of the Mode 2 to Mode 3 transition, the main archaeological assemblage of this subunit comprises centripetal cores, with diverse and standardised reduction sequences aimed at obtaining small and medium-sized flakes, and a number of Levallois cores combined with typical Mode 2 elements, such as large cutting tools (RodríguezÁlvarez, 1997; Carbonell et al, 2001; Rodríguez-Álvarez, 2004; Ollé et al., 2013).

Up to now, 42 RMU of quartz $(n=215)$, and 148 RMU of quartzite $(n=869)$ have been identified from subunit TD10.1. From among these, it has been possible to identify 15 Formatted: Font: Italic Formatted: Font: Italic

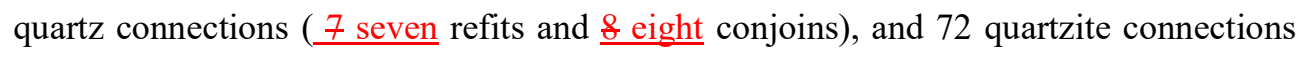
(38 refits and 34 conjoins) (López-Ortega et al, 2015). Of these, 80 flakes and broken flakes of quartzite, belonging to 34 refit groups, are useful for our purposes (Figure 3). Two to five refitting flakes form most of these groups. This means that we have as many as $\underline{5 \text { five }}$ flakes produced by a single knapper.

Figure 3

Abric Romani (Barcelona, Spain)

The Abric Romaní rock shelter is located in the NE of the Iberian Peninsula, approximately $50 \mathrm{~km}$ west of Barcelona. The site is located in the town of Capellades, in the tufa formations that rise on the right bank of the Anoia River. The stratigraphy is 
composed of $20 \mathrm{~m}$ of well-stratified travertine sediments dated by U-Series as being between 40 and $70 \mathrm{ka}$ (Vaquero et al., 2013).

The archaeological units tested for this study are levels $\mathrm{J}$ and $\mathrm{M}$, aged between 45 and 54 ka, which also show well-defined discrete accumulations (Vaquero and Pastó, 2001). Technologically, the lithic assemblage of both levels $\mathrm{J}$ and M correspond to Mode 3, here characterised by discoid and expeditious knapping methods.

Level $\mathrm{J}$ has yielded 7,000 lithic artefacts, and 8,460 faunal remains. There are two main archaeostratigraphic units: sublevels $\mathrm{Ja}$ and $\mathrm{Jb}$, which have been distinguished only in the central area of the occupation. The U-series dates are $c .49 \mathrm{ka}$ BP for the overlying tufa $(49.3 \pm 1.6$ and $49.2 \pm 2.9 \mathrm{ka} \mathrm{BP})$ and around $50 \mathrm{ka} \mathrm{BP}(50.0 \pm 1.6$ and $50.8 \pm 0.8$ ka BP) for the underlying tufa (Bischoff et al., 1988). In addition, a charcoal sample has been dated as $47.1 \pm 2.1{ }^{14} \mathrm{C}$ ka BP (NZA-2316) (Vaquero et al., 2012). According to the refits and the macroscopic characteristics of the raw materials, more than $500 \mathrm{RMU}$ have been identified, each corresponding to a singular technical event. Moreover, 262 refitting groups, totalling 719 artefacts, have been found. In addition, level $\mathrm{J}$ has also yielded 50 hearths that seem to have spatially structured the site.

The tufa layer immediately above level M is dated at around 51.8 $\pm 1.4 \mathrm{ka}$ BP (Bischoff et al., 1988; Vallverdú et al., 2012). The number of recorded archaeological remains is 18,946, of which 7,614 are faunal remains, 6,084 are lithic remains, 114 are wood imprints, 260 charcoal fragments- and 37 hearths. In level $\mathrm{M}$ it has been possible to identify 76 RMU (under study). Moreover, 216 refitting groups, totalling 827 artefacts, have been found. 
We have selected the refit groups with the most connecting flakes from a single core

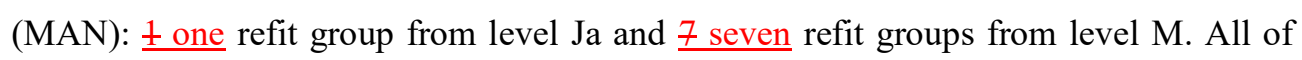

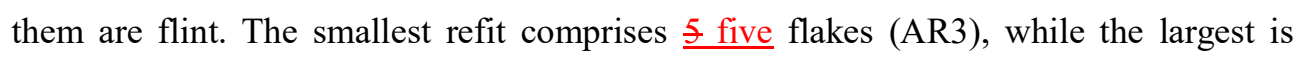
made up of 36 flakes (AR8) (Figure 4).

Figure 4

\section{Results}

The total sample set analysed comprised 1,355 flakes and broken flakes. Of these, 80 are from Gran Dolina (level TD10.1), 116 from Abric Romaní (level Ja and M) and 1,159 are from the experimental programme. Of the 1,355 pieces, 971 were complete flakes and 384 were broken flakes.

Tables 2 and 3 show the frequency at which the technical features of hand preference appear in the experimental sample together with Abric Romaní refit groups (Table 2), and Gran Dolina refit groups (Table 3). Interestingly, there are differences between the archaeological and experimental samples: $63 \%$ of the variables included in the technical features were not identified in any of the 80 flakes from level TD10.1 of Gran Dolina, and $27 \%$ of these variables were not identified in any of the 116 flakes from Abric Romaní. In contrast, just $3.26 \%$ of the variables could not be identified in any of the 1,159 experimental flakes. Furthermore, two variables of the technical features were not identified in any of the 196 archaeological flakes analysed: the distal location of hackles, and the sinuous inclination of the striking platform. Both these variables tended 
to appear in low frequencies in the experimental sample. Therefore, and taking into account the figures, it is likely that the presence/absence of some of the variables is directly linked to the number of flakes analysed: the more flakes detached by a single knapper, the more the possibilities of them containing all the variables included in each technical feature. The frequencies of each technical feature will be used in the correspondence analysis to identify the hand laterality of prehistoric knappers.

\section{Table 2}

\section{Table 3}

In order to ascertain the minimum number of flakes required to identify at $100 \%$ confidence the hand laterality of the knapper, we first performed a correspondence analysis, including all the archaeological and experimental samples. Figure 5 shows all the samples, and the way the archaeological groups of refits are located around the experimental ones. Compared to Figure 2 (only experimental samples) we can see that both left_- and right-handed experimental knappers situate closer, concentrate, hence losing their spatial variability. This is probably because there are too few flakes in some of the archaeological refits, some of them having just $\underline{\underline{z} \text { two }}$ or $\underline{\underline{z} \text { three }}$ refit flakes.

\section{Figure 5}

Because of this distortion in the distribution pattern of the experimental groups, a second correspondence analysis was undertaken, this time excluding all archaeological refit groups with less than $\underline{5 \text { five }}$ flakes. By doing this we lose most of the Gran Dolina

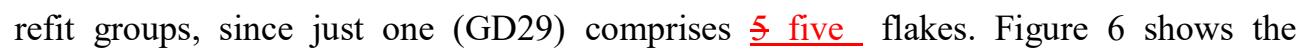


distribution of all the remaining samples, which is more similar to the experimentalonly pattern (Figure 2). Although the relative position of the right- and left-handed samples is correct (right-handers above the $\underline{X}$ abseise axis, left-handers below), the experimental samples maintain the distorted pattern, particularly the position of the sample $\mathrm{R}-\mathrm{Nu}$ (a right-handed participant), which is below the $\mathrm{X}$ abseise-axis, in a similar position to some of the left-handed participants. In other words, the-individual $\mathrm{R}-\mathrm{Nu}$ locates outside the sector of her true hand preference. This means that although better, this sampling is not selective enough to give a perfect fit to the experimental, real pattern. In summary, byby analysing $\underline{5 \text { five } 5}$ flakes may lead to a false positive result.

Figure 6

However, given that few flakes make up most of the archaeological samples (Figure 3 and 4) we decided to perform a series of new simulations involving downscaled experimental samples, instead of removing archaeological groups from the analysis. As Table 1 shows, the number of flakes per group from the experimental sample ranged between 47 and 140 flakes. Consequently, we downscaled each experimental group of refits to fewer flakes per knapper. This simulation was made by taking the median of each variable, preserving the weight of each technical feature from the original distribution pattern. We reduced the experimental sample to $\underline{5}$ five flakes (Figure 7a), $\underline{6}$

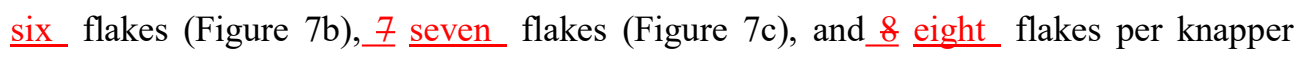
(Figure 7d), the last group showing the same pattern between the downscaled experimental subsamples and the original experimental sample group. Therefore, $\underline{8 \text { eight }}$ is the minimum number of flakes required to identify the hand laterality of a knapper above a confidence level of $93.75 \%$. 
These simulations allowed us to obtain the confidence rate for each downscaling of the experimental sample. As Figure 7a shows, the distribution pattern of the downscaled experimental subsample is quite similar to the pattern of the original experimental

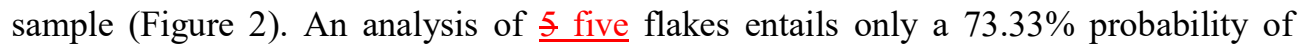

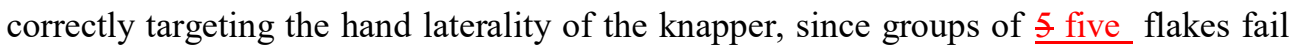
to achieve their correct position in the plot: individuals $\mathrm{L}_{-} E t, \mathrm{~L}_{-} 4, \mathrm{~L}_{-} 3, \mathrm{R} \_4$ and $\mathrm{R}$ 3 are positioned outside the sector of their true hand preference, when analysing just $\underline{5}$ five flakes. Actually, these individuals are showing false positives. Besides, the margin of success is greater for the right-handed population (75\%), than for the left-handed population $(71.42 \%)$.

By analysing $\underline{6 \text { six }}$ flakes (Figure $7 \mathrm{~b}$ ) still we still have some individuals that are positioned outside the sector of their true hand preference. These individuals are R-Mn, L_1, L-2, L-3, L-4. Interestingly, by analysing $\underline{6 \text { six }}$ flakes (Figure 7b) the probability of correctly identifying the hand preference of the sample reduces to $66.66 \%$, even though with this number the probability of correctly assigning right-handers is higher $(87.5 \%$, with left-handers being only $42.85 \%)$. Nevertheless, by analysing 7 seven flakes the improvement in the results is notable, since the probability of targeting the hand preference of the knapper rises to $93.33 \%$ (Figure 7c). In this case, only one group of flakes (L_3) belonging to a left-handed knapper is wrongly positioned as a right-handed individual. Therefore, the margin of error, the probability of a false positive has decreased to $6.66 \%$. Finally, analysing $\underline{\& \text { eight }}$ flakes per knapper guarantees the correct distribution of the experimental population with regard to their hand preference (Figure 7d), above a confidence level of $93.75 \%$. 
Figure 7

With this information, we looked once again at the archaeological sample group using refits formed by $\_$eight or more flakes. Only $\underline{\underline{5}} \underline{\text { five }}$ groups of refits fulfil this condition, all from the Abric Romaní site: $\underline{4}$ one from level Ja (sample AR1), and 4 four from Formatted: Strikethrough level M (samples AR5; AR6; AR7; AR8). Figure 8 shows the distribution of these samples, where all the archaeological groups fit the right-handed pattern of knappers, similar to that of the experimental participant R_A_B. However, experimental righthanded knapper R_Nu appears in the area of left-handed knappers, showing a false positive. This false positive means that there is still a small margin of error $(6.66 \%)$. This fact particularly affects the archaeological group of refits AR5, nearest the $\underline{X}$ abseise axis, which varies its position depending on whether the experimental knapper R_Nu is included in (Figure 8), or excluded from (Figure 9) the analysis. In the first case, AR5 appears as a right-handed knapper; in the second case, she he/she is lefthanded.

\section{Figure 8}

Figure 9

In summary, right-handed Neanderthals knapped four of the five groups of flakes detached at the Abric Romaní with about 94\% level of certainty, while one remains difficult to assign to a group. In Gran Dolina-TD10-1, only one group of flakes (GR29) contains enough information enough to be $73.33 \%$ certain that they were produced by a right-handed knapper. 


\section{Discussion}

The aim of this paper is to apply a method to the archaeological record that allows us to identify the hand laterality of our ancestors, and discern when and how this feature, which is most prominent in humans, appeared in our evolutionary history. The importance of this issue lies in the organisation of the brain, where our motor, sensory, and cognitive functions are structured accord with aceording to this laterality.

Previous approaches to the hand laterality of our ancestors have mainly involved the hominin remains found at certain sites. However, these remains are scarce and do not always include the body parts that provide information on this question. Other approaches using stone tools, such as use-wear analysis, have been successful, but require the tools both to have been both used sufficiently; and be well preserved. Other proxies drawn from the study of single technological features of flakes (i.e., Toth, 1985; Rugg and Mullane, 2001; Domínguez-Ballesteros and Arrizabalaga, 2015) have been questioned from the beginning by authors such as Patterson and Sollberger (1986), Pobiner (1999), and Bargalló and Mosquera (2014). These papers discuss the reliability of finding out the hand preference of one individual by using iust only one single technical feature.

The study presented here applies a previously published method (Bargalló and Mosquera $_{2}$ 2014), which deals with handedness in human evolution by analysing a combination of certain technical features of the most widely-produced stone tools in the Pleistocene world: flakes. We used a multivariate statistical analysis (Correspondence 
analysis), since alternative classification methodologies (i.e., Binary Logistic

Regression and applied a simple Machine Learning algorithm) could not significantly outperform the null model (i.e., random laterality attribution).

The selected method requires flakes produced by the same knapper, meaning that these flakes must be identified from the archaeological assemblage. It is quite difficult to isolate an individual knapping event in an archaeological assemblage, given that most archaeological levels are actually palimpsests. Preliminary archaeostratigraphic approaches to isolating the remains of each living floor, and a subsequent search for refits, are required to identify singular events (Lucas, 2005; Bailey, 2007; Bargalló et al., 2015; Machado et al., 2015). Because these singular knapping events may involve more than one core (Vaquero, 2008), it is necessary to identify a unique core and the flakes that refit one another. However, ethnographic records show that different knappers (Stout, 2002; Bril et al., 2005) may have worked on the same single core. Nevertheless, the archaeological lithic samples we used in this study have the following characteristics: 1) all the archaeological groups of refits are formed by relatively few pieces, never exceeding forty flakes, and 2) the technical features of the flakes are completely homogeneous within each group of refits, suggesting that they were all produced by the same person.

The matter of how much raw material may condition the analysis has been solved by selecting archaeological refit groups of quartzite for Atapuerca and flint from Abric Romaní. Both rock types were frequently used in prehistory, as well as at each of these sites, and they are good quality materials, retaining the maximum number of technical features produced by the knapping process, unlike quartz, the 
large crystal_structures makes it difficult to preserve many striking platforms (de Lombera-Hermida, 2009).

In addition, this paper also highlights other potential uses of refit studies. Until now, they have been used to analyse the spatial distribution of remains within occupations; to understand the way the tools were produced; to know identify how hominins organised the tasks performed inside the settlements; and to identify the movements of the individuals within these activity areas (Cahen et al., 1979; Hofman, 1981; Bodu et al., 1990; Ashton, 2004; Turq et al., 2013). Now, refits can also be used to facilitate the identification of individuals and provide an understanding of their technological cognition.

In this sense, studying the handedness of the fossil hominins is not mere "storytelling", providing anecdotal information, but the information may help us understand the development of the complex brain organisation during human evolution, and to discover how individuals engaged within their communities. In the words of Foulds: “...this is a reference to an individual agent within a wider society founded on the social relationships that they both create and maintain, irrespective of how they conceived of themselves" (Foulds, 2014: 13).

\section{Conclusions}


The minimum number of flakes necessary to successfully identify hand laterality at

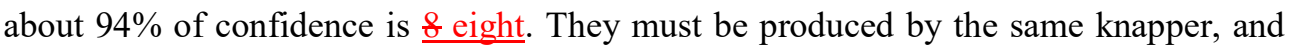
the only way to ensure this from the archaeological record is to find $\underline{8 \text { eight flakes that }}$ refit one other because they were produced from a single core-knapping event. In addition, there is no single technical feature that provides information about hand

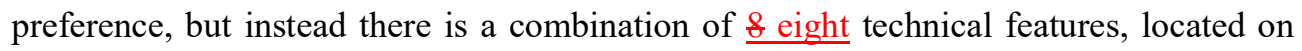
the striking platforms and the ventral surfaces. Raw material is not relevant in the case of the most-widely used rocks in Europe, flint and quartzite, since the majority retain the technical features required for analysis. The exception to this is quartz, where many flakes from the striking platform are lost during the percussion. Expertise is not an issue either, since the technical features analysed here only correlate only with handedness, and not the technical quality of the tools (Bargalló and Mosquera, 2014).

Our results indicate that just one pre-Neanderthal knapper from TD10.1 at Gran Dolina (Atapuerca) may be suitable for analysis, since only one refit group containing $\underline{5 \text { five }}$ quartzite flakes was found. It has been ascertained with a $73.3 \%$ confidence rate that this individual was right-handed. The Abric Romaní Neanderthal knappers provide us

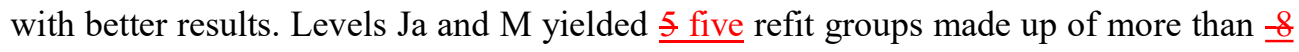
eight flakes, allowing us to clearly distinguish the presence of four right-handers, with the hand preference of one remaining unclear.

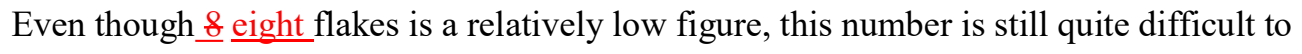
obtain at many archaeological sites. This is the case of Gran Dolina-TD10.1, which up to now has yielded 29 groups of quartzite refits from knapping sequences, none of

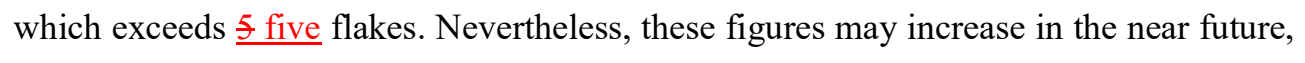


and more success may be seen when applying the method to the Neogene chert assemblage, which is much more numerous, but also much more difficult to refit, due to the poor preservation of this rock type.

The possibility of identifying the handedness of our ancestors, in this case from $300 \mathrm{ka}$ and $50 \mathrm{ka}$ ago at Gran Dolina-TD10.1 and Abric Romaní, respectively, signifies a big step forward in the field of human evolution, no matter the age of the samples. Further study should eventually allow us to fix the time when handedness arose and, by extension, know at what point brain laterality developed in humans at both the individual and population levels, as well as which hominin species were partially or totally lateralised. It is possible that our earliest ancestors started to display handedness, but perhaps more sporadically, as seen in living chimpanzee populations. We will also be able to understand the progression of this cognitive feature through our phylogeny, and whether it was a progressive change or one that appeared suddenly. In addition, we will be able to study the role that social and cultural environments may have played in the evolution of this characteristic. Our method ensures this goal through studying the knapping activities of our ancestors, one of the best-recorded tasks with well-preserved remains.

\section{Acknowledgments}

The authors would like to thank F. Romagnoli for her comments and suggestions on the first draft. This work has been carried out with the financial support of Spanish Ministerio de Economía y Competitividad projects HAR2012-32548-HIST, and 
CGL2012-38434-C03-03.AB has been founded from the European Union's Horizon 2020 research and innovation programme under the Marie Sklodowska-Curie Action grant agreement PREKARN $n^{\circ} 702584$. SL is supported by the Ramón y Cajal programme through the grant RYC-2012-01043. The authors are grateful to the participants in the experimental tests, and to G. Chacón, F. Romagnoli and M. Vaquero from Abric Romaní, and A. de Lombera-Hermida, and E. López-Ortega, from Gran Dolina, for working on the archaeological refits at the two sites.

\section{References}

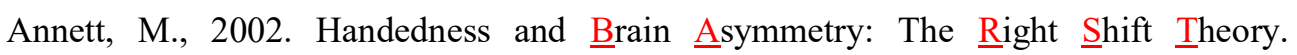
Psychology Press, Hove.

Arnold, L.J., Demuro, M., In press. Insights into TT-OSL signal stability from singlegrain analyses of known-age deposits at Atapuerca, Spain. Quaternary Geochronology. DOI: 10.1016/j.quageo.2015.02.005.

Arnold, L.J., Demuro, M., Parés, J.M., Pérez-González, A., Arsuaga, J.L., Bermúdez de Castro, J.M., Carbonell, E.,2015. Evaluating the suitability of extended-range luminescence dating techniques over early and Middle Pleistocene timescales: published datasets and case studies from Atapuerca, Spain. Quaternernary Internationat. 389, 167-190.DOI: 10.1016/j.quaint.2014.08.010. 
Ashton, N., 2004. The role of refitting in the British Lower Palaeolithic: a time for reflection. In: Walker, E.A., Wenban-Smith, F., Healy, F. (Eds.), Lithics in Action. Oxbow Books, Oxford, pp. 57-64.

Bailey, G., 2007. Time perspectives, palimpsest and the archaeology of time. Journal of Anthropological Archaeology 26, 198-223.

Bargalló, A. Mosquera, M., 2014. Can hand laterality be identified through lithic technology. Laterality 19, 37-63.

Bargalló, A., Gabucio, M.J., Rivals, F., 2015. Puzzling out a palimpsest: Testing an interdisciplinary study in level O of Abric Romaní, Quatern_ary Int_ernationat_417,-5165. DOI: 10.1016/j.quaint.2015.09.066.

Berger, G.W., Pérez-González, A., Carbonell, E., Arsuaga, J.L., Bermúdez de Castro, J.M., Ku, T., 2008. Luminescence chronology of cave sediments at the Atapuerca paleoanthropological site, Spain. Journal of Human Evolution. 55, 300-311.

Bermúdez de Catro, J.M. Bromage, T.G. Fernàndez Jalvo, Y., 1988. Buccal striations on fossil human anterior teeth: Evidence of handedness in the middle and early Upper Pleistocene. Journal of Human Evolution. 17, 403-412.

Bermúdez de Castro, J.M. Martinón-Torres, M. Sarmiento, S. Lozano, M. Arsuaga, J.L. Carbonell, E., 2003. Rates of anterior teeth wear in Middle Pleistocene hominins from 
Sima de los Huesos (Sierra de Atapuerca, Spain). Proceedings of the National Academy of Sciences, USA 100, 11992-11996

Bischoff, J.-L., Julia, R. ${ }_{2}$ Mora, R., 1988. Uranium-series dating of the Mousterian occupation at the Abric Romani, Spain. Nature-332, 68-70.

Bleed, P., 2004. Refitting as aggregate analysis. In: Hall, C.T., Larson, M.L. (Eds.), Aggregate Analysis in Chipped Stone. University of Utah Press, Salt Lake City, pp.184198.

Bodu, P., Karlin, C., Ploux, S., 1990. Who's who? The Magdalenian flintknappers of Pincevent (France), In: Czielsa, E..2 Eickhoff, S.2 Arts, N., Winter, E. (Eds.), The Big Puzzle. International Symposium on Refitting explanation. Stone Artefacts. Monrepos. Studies in Modern Archaeology, Holos, Bonn, pp.143-163.

Comment [A27]: Is this needed if it in Curr. Anthropol. ?

Comment [A28R27]: Ok I corrected

Bril, B., Roux, V., Dietrich, G., 2005. Stone knapping: Khambhat (India), a unique opportunity? In: Roux, V., Bril, B. (Eds), Stone Knapping: the Necessary Conditions for a $\underline{\text { Uniquely }}$ Hominin Behaviour. McDonald Institute Monographs, pp. 53-71.

Bromage, T.G., Boyde, A., 1984. Microscopic criteria for the determination of directionality cutmarks on bone. American Journal of Physical Anthropology 65, 359Comment [A29]: PLACE OF PUBLICATION AND IS IT MCDONALD? (one word)

Comment [A30R29]: Ok I corrected $\underline{366 .}$ 
Bromage, T.G. Bermúdez de Castro, J.M. Fernández-Jalvo, Y., 1991. The SEM in taphonomic research and its application to studies of cutmarks generally and the determination of handedness specifically. Anthropologie Brno XXIX, 163-169.

Cahen, D., Keeley, L., Van Noten, F., 1979. Stone tools, toolkits and human behavior in Prehistory. Current Anthropology 20, 661-683.

Carbonell, E., Mosquera, M., Ollé, A., Rodríguez-Álvarez, X.P., Sahnouni, M., Sala, R., Verges, J.M., 2001. Structure morphotechnique de l'industrie lithique du Pléistocéne inférieur et moyen d'Atapuerca (Burgos, Espagne). L'Anthropologie 105, 259-280.

Carbonell, E. (Ed.), 2012. High Resolution Archaeology and Neanderthal Behaviour. Springer, New York.

Comment [A31]: Place of publication?

Comment [A32R31]: OK I did

Carretero, J.M., Arsuaga, J.L., Lorenzo, C., 1997. Clavicles, scapule and humeri from the Sima de los Huesos site (Sierra de Atapuerca, Spain). Journal of Human Evolution $33,357-408$.

Cooper, J., Qiu, F., 2006. Expediting and standardizing stone artifact refitting using a computerized suitability model. Journal of Archaeological Science 33, 987-998.

Corballis, M.C., 2003. From mouth to hand: Gesture, speech, and the evolution of righthandedness. Behavioral and Brain Sciences 26, 199-260. 
Cziesla, E., 1990. On refitting of stone artefacts. In: Cziesla, E., Eickhoff, S., Arts, N., Winter, E. (Eds.), The Big Puzzle. International Symposium on Refitting Stone Artefacts.

Cziesla, E., Eickhoff, S., Arts, N., Winter, E. (Eds.), 1990. The Big Puzzle. International Symposium on Refitting Stone Artefacts, Holos, Bonn.

De Lombera-Hermida, A., 2009 The scar identification of lithic quartz industries. In: Sternke, F. Costa, L.J., Eigeland, L. (Eds.), Non-flint Raw Material Use in Prehistory. Old Perjudices and New Direction. Proceedings of the XV World Congress of the UISPP. BAR International Series, Archaeopress, Oxford, pp. 5-11.

Dominguez-Ballesteros, E., Arrizabalaga, A., 2015. Flint knapping and determination of human handedness. Methodological proposal with quantifiable results. Journal of Archaeological Science: Reports 3, 313-320.

Falguéres, C., Bahain, J.J., Yokoyama, Y., Arsuaga, J.L., Bermúdez de Castro, J.M., Carbonell, E., Bischoff, J.L., Dolo, J.M., 1999. Earliest humans in Europe: the age of TD6 Gran Dolina, Atapuerca, Spain. Journal of Human Evolution 37, 343-352.

Falguères, C., Bahain, J.-J., Bischoff, J.L., Pérez-González, A., Ortega, A.I., Ollè, A., Quiles, A., Ghaleb, B., Moreno, D., Dolo, J.-M., Shao, Q., Vallverdú, J., Carbonell, E., Bermúdez de Castro, J.M., Arsuaga, J.L., 2013. Combined ESR/U-series chronology of Acheulian hominid-bearing layers at Trinchera Galería site, Atapuerca, Spain. Journal of Human Evolution 65, , 168-184. 
Falk, D., 1987. Brain lateralisation in primates and its evolution in hominids. Yearbook of Physical Anthropology 30, 107-125.

Fiore, I. Bondioli, L. Radovcic, J. Frayer, D.W., 2015. Handedness in the Krapina Neandertals: A re-evaluation. PaleoAnthropology 2015, 19-36.

Foulds, F., 2014. Invisible Individuals, Visible Groups: On the evidence for individuals and groups at the Lower Palaeolithic site of Caddington, Bedfordshire, UK. In: Foulds, F.W.F. Drinkall, H.C. Perri, A.R. Clinnick, D.T.G. Walker, J.W.P. (Eds.) Wild things: recent advances in Palaeolithic and Mesolithic research. Oxford, Oxbow Books, pp. 1240.

Frayer, D.W., Fiore, I., Lalueza-Fox, C., Radovcic, J., Bondioi, L., 2010. Right handed Comment [A38R37]: OK I introduced

Neandertals: Vindija and beyond. Journal of Anthropological Sciences 88, 113-127.

Frayer, D.W.2 Lozano, M.2 Bermúdez de Castro, J.M..2 Carbonell, E.2 Arsuaga, J.L..2 Radovcic, J.2 Fiore, I.2 Bondioli, L., 2012. More than 500,000 years of right-handedness in Euope_ Laterality: Asymmetries of Body, Brain and Cognition 17 , 51-69.

Gómez de Soler, B., 2007. Áreas de captación y estrategias de aprovisionamiento de rocas silíceas en el nivel L de Abric Romaní (Capellades, Barcelona). M.Sc. Dissertation, Universitat Rovira i Virgili. 
Hall, C.T., 2004. Evaluating prehistoric hunter-gatherer mobility, land use, and technological organization strategies using minimum analytical nodule analysis. In: Hall, C.T., Larson, M.L. (Eds.), Aggregate Analysis in Chipped Stone. University of Utah Press, Salt Lake City, pp. 139-155.

Hammer, Ø., Harper, D.A.T., Ryan, P.D., 2001. PAST: Paleontological Statistics Software Package for Education and Data Analysis. Palaeontologia Electronica, 4, 9. http://palaeoelectronica.org/2001 1/past/issue1 01.htm

Hammer, Ø., Harper, D.A.T., Ryan, P.D., 2008. PAST: Palaeontological Statistics, ver. 1.81. http://folk.uio.no/ohammer/past/past.pdf title?

Comment [A40]: Yes it is the full title.

Hofman, J., 1981. The refitting of chipped-stone artifacts as an analytical and interpretive tool. Current Anthropology 22, 691-693.

Holloway, R.L., 1976. Palaeoneurological evidence for language origins. In: Harnad,

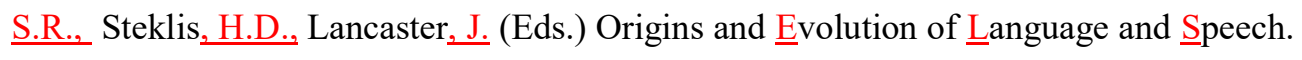
New York Academy of Sciences, New York, pp. 330-348

Hopkins, W.D., 1996. Chimpanzee handedness revisited: 55 years since Finch Psuchonomic Bulletin and Review 3, 449-457.

Hopkins, W.D., Cantalupo, C., 2005. Individual and setting differences in the hand preferences of chimpanzees (Pan troglodytes): A critical analysis and some alternative explanations. Laterality: Asymmetries of Body, Brain and Cognition 10, 65-80. 
Hopkins, W.D., Wesley, M.J., Izard, M.K., Hook, M.2 Schapiro, M.J.2 2004.

Chimpanzees (Pan troglodytes) are predominantly right-handed: replication in three populations of apes. Behavioral Neuroscience 118, 659-663.

Knecht, S., Dräger, B., Deppe, M.2 Bobe, L., Lohman, H., Flöel, A., Ringelstein, E.-B.. Henningsen, H., 2000. Handedness and hemispheric language dominance in healty humans. Brain 123, 2512-2518.

Lazenby, R.A., 2002. Skeletal biology, functional asymmetry and the origins of 'handedness'. Journal of Theoretical Biology 218, 129-138.

Llorente, M., 2011. Lateralidad manual y especialización hemisférica en chimpancés (Pan troglodytes). Evaluación experimental y obervacional. Ph.D. Dissertation, $\underline{\text { Universitat Ramon Llull. }}$

Llorente, M., Mosquera, M., Fabré, M., 2009. Manual laterality for simple reaching and bimanual coordinated task in naturalistic housed Pan troglodytes. International Journal of Primatology 30 , 183-197.

Llorente, M., Riba, D., Palou, L., Carrasco, L., Mosquera, M., Colell, M., Feliu, O., 2011. Population-level right-handedness for a coordinated bimanual task in naturalistic housed chimpanzees: replication and extension in 114 animals from Zambia and Spain. American Journal of Primatology 73,281-290. 
Larson, M.L., 2004. Chipped stone aggregate analysis in archaeoloegy. In: Hall, C.T., Larson, M.L. (Eds.), Aggregate Analysis in Chipped Stone. University of Utah Press,

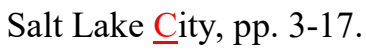

López-Ortega, E.2 Bargalló, A.2 de Lombera-Hermida, A.2 Mosquera, M.2 Ollé, A..2 Rodríguez-Álvarez, X.P., In press. Quartz and quartzite refits at Gran Dolina (Sierra de Atapuerca, Burgos): Connecting lithic artefacts in the Middle Pleistocene unit of TD10.1. Quaternary International DOI:10.1016/j.quaint.2015.09.026.

Lozano, M. Mosquera, M. Bermúdez de Castro, J.M. Arsuaga, J.L. Carbonell, E., 2009. Right handedness of Homo heidelbergensis from Sima de los Huesos Atapuerca, Spain 500,000 years ago. Evolution and Human Behavior 30, 369-376.

Lucas, G., 2005. The Arcaheology of Time. Routledge, London.

Machado, J., Mallol, C., Hernández, C.M., 2015. Insights into Eurasian Middle Paleolithic settlement dynamics: the palimpsest problem. In: Conard, N.J., Delagnes, A. (Eds.), Settlement Dynamics of the Middle Paleolithic and Middle Stone Age, vol IV. Kerns Verlag, Tübingen, pp. 361-382.

McGrew, W.C., Marchant, L.F., 1997. On the other hand: Current issues in and metanalysis of the behavioural laterality of hand function in nonhuman primates. Yearbook of Physical Anthropology 40, 201-232. 
McGrew, W.C., Marchant, L.F., 2001. Ethological study of manual laterality in the chimpanzees of the Mahale mountains, Tanzania. Behavioural Processes 138, 329-358.

McPherron, S.P., Alemseged, Z., Marean, C.W., Wynn, J.G., Reed, D., Geraads, D., Bobe, R., Bearat, H.A., 2010. Evidence for stone-tool-assisted consumption of animal tissues before 3.39 million years ago at Dikika, Ethiopia. Nature 466, 857-860.

Moreno, D., Falguères, C., Pérez-González, A., Voinchet, P., Ghaleb, B., Despriée, J., Bahain, J.J., Sala, R., Carbonell, E., Bermúdez de Castro, J.M., Arsuaga, J.L., In press. New radiometric dates on the lowest stratigraphical section (829 TD1 to TD6) of Gran Dolina site (Atapuerca, Spain). Quaternary Geochronology. DOI:10.1016/j.quageo.2015.05.007

Mosquera, M., Llorente, M., Riba, D., Lorenzo, C., Carbonell, E., Feliú, O., 2007. Ethological study of manual laterality in naturalistic housed chimpanzees (Pan troglodytes) from the Mona Foundation Sanctuary (Girona, Spain). Laterality: Asymmetries of Body, Brain and Cognition 12 , 19-30.

Mosquera, M., Geribàs, N., Bargalló, A., Llorente, M., Riba, D., 2012. Complex tasks force hand laterality and technological behaviour in naturalistically housed chimpanzees: inferences in hominin evolution. The Scientific World Journal zo12. DOI:10.1100/2012/514809. numbers?

Comment [A42R41]: Ok I corrected

Odell, G.H., 2004. Lithic Analysis. Kluwer Academic/Plenum Publishers, New York. 
Ollé, A.. 2003. Variabilitat I patrons funcionals en els Sistemes Tècnics de Mode 2. Anàlisi de les deformacions d'ús en els conjunts lítics del Riparo Estreno de Grotta Paglicci (Rignamo Garganico, Foggia), Áridos (Arganda, Madrid) i Gatería-TN (Sierra de Atapuerca, Burgos). Ph.D. Dissertation, Universitat Rovira i Virgili.

\section{Formatted: Line spacing: Double}

Ollé, A., Mosquera, M., Rodríguez-Álvarez, X.P., de Lombera-Hermida, A., GarcíaAntón, M.D., García-Medrano, P., Peña, L., Menéndez, L., Navazo, M., Terradillos, M., Bargalló, A., Márquez, B., Sala, R., Carbonell, E., 2013. The Early and Middle Pleistocene technological record from Sierra de Atapuerca (Burgos, Spain). Quaternary International 295, 138-167.

Patterson, L.W., Sollberger, J.B., 1986. Comments on Toth's right-handedness study. Lithic Technology 15, 109-111.

Pickering, T.R., Hensley-Marschand, B., 2008. Cutmarks and hominid handedness. Journal of Archaeological Science 35, 310-315.

Pobiner, B.L., 1999. The use of stone tools to determine handedness in hominids. Current Anthropology 40, 90-92.

Poza-Rey, E.M., Lozano, M., Arsuaga, J.M., 201․ Brain asymmetries and handedness in the specimens from the Sima de los Huesos site (Atapuerca, Spain). Quaternary International 433, 32-44 
Rodríguez, J., Burjachs, F., Cuenca-Bescós, G., García, N., Van der Made, J., PérezGonzález, A., Blain, H.A., Expósito, I., López-García, J.M., García-Anton, M., Allué, E., Cáceres, I., Huguet, R., Mosquera, M., Ollé, A., Rosell, J., Parés, J.M., RodríguezÁlvarez, X.P., Díez, J.C., Rofes, J., Sala, R., Saladié, P., Vallverdú, J., Bennasar, L., Blasco, R., Bermúdez de Castro, J.M., Carbonell, E., 2011. One millions years of cultural evolution in a stable environment at Atapuerca (Burgos, Spain). Quaternary Science Reviews 30, 1396-1412.

Rodríguez-Álvarez, X.P., 1997. Sistemas técnicos de producción lítica del Pleistoceno Inferior y Medio en la Península Ibérica: variabilidad tecnológica entre yacimientos del Noreste y de la Sierra de Atapuerca. Ph.D. Dissertation, Universitat Rovira i Virgili. Rodríguez-Álvarez, X.P., 2004. Technical Systems of Lithic Production in the Lower and Middle Pleistocene of the Iberian Peninsula: Technological Variability between North-Eastern Sites and Sierra de Atapuerca Sites., BAR International Series S1323. Archaeopress, Oxford.

Roebroeks, W., 1988. From Find Scatters to Early Hominid Behavior: a Study of Middle Palaeolithic Riverside Settlements at Maastricht-belvedere (The Netherlands). Analecta Praehistorica Leidensia 25, 1-16.

Rugg, G., Mullane, M., 2001. Inferring handedness from lithic evidence. Laterality: Asymmetries of Body, Brain and Cognition 6, 247-259.
Comment [A45]: Isn't this Van der Made, J., ?

Comment [A46R45]: Yes I corrected

Comment [A47]: Reformat and cite correctly - are there editors, place of publication, page numbers etc?

Comment [A48R47]: Ok I corrected

Comment [A49]: Reformat and cite correctly - are there editors, place of publication, page numbers etc?

Comment [A50R49]: Ok I corrected 
Schäfer, J., 1990. Conjoining of artefacts and consideration of raw-material: their application at the Middle Palaeolithic site of the Schweinskopf-Karmelenberg. In: Cziesla, E., Eickhoff, S., Arts, N., Winter, E. (Eds.), The Big Puzzle. International Symposium on Refitting Stone Artefacts. Holos, Bonn, pp. 83-100.

Schick, K., Toth, N., 2009. African origin. In: Scarre, C. (Ed.), The Human Past: World Comment [A51]: Please make sure this is corrected and matches earlier citations - why the 1987 ?

Prehistory and the Development d Human Societies. Thames \& Hudson, Portland,

Ore, USA, pp 46-83.

Shaw, C.N., 2011. Is "hand preference" coded in the hominin skeleton? An in-vivo study of bilateral morphological variation. Journal of Human Evolution 61, 480-487.

Soto, M., Gómez de Soler, B., Vallverdú, J., Vaquero, M., 2014. Potential siliceous sources during prehistory: Results of prospecting in the east margin of the Ebro Basin (NE Iberian Peninsula). Journal of Lithic Studies 1, 293-318.

Stout, D., 2002 Skill and cognition in stone tool production. Current Anthropology 43, 693-722

Teixeira, L.A., Okazaki, V.H.A., 2007. Shift of manual preference by lateralized practice generalizes to related motor tasks. Experimental Brain Research 183, 417-423.

Toth, N., 1985. Archaeological evidence for preferential right handedness in the lower and middle Pleistocene and its possible implications Journal of Human Evolution 14, 607-ㅁ⒕ 
Turq, A., Roebroeks, W., Bourguignon, L., Faivre, J.P., 2013. The fragmented character of Middle Palaeolithic stone tool technology. Journal of Human Evolution 65, 641-655.

Uomini, N.T., 2009. The prehistory of handedness: Archaeological data and comparative ethology. Journal of Human Evolution 57, 411-419.

Vallverdu, J., Gomez de Soler, B., Vaquero, M., Bischoff, J. L., (2012). The Abric Romani site and the Capellades region. In: Carbonell, E. (Ed.), High Resolution Archaeology and Neandertal Behavior: Time and Space in Level J of Abric Romaní (Capellades, Spain). Vertebrate Paleobiology and Paleoanthropology. Springer, New York. pp. 19-46.

Vaquero, M., 2008. The history of stones: behavioural inferences and temporal resolution of an archaeological assemblage from the Middle Palaeolithic. Journal of Archaeological Science 35, 3178-3185.

Vaquero, M.2 Chacón, M.G.2 García-Antón, M.D.2 Gómez de Soler, B.2 Martínez, K.2 Cuartero, F., 2012. Time and space in the formation of lithic assemblages: The example of Abric Romaní Level J. Quaternary International 247, 162-181.

Vaquero, M., Pastó, I., 2001. The definition of spatial units in middle Palaeolithic sites: the hearth-related assemblages. Journal of Archaeological Science 28, 1209-1220. 
Vaquero, M., Allué, E., Bischoff, J.L., Burjachs, F., Vallverdú, J., 2013. Environmental, depositional and cultural changes in the Upper Pleistocene and Early Holocene: the Cinglera del Capelló sequence (Capellades, Spain). Quaternaire 24, 49-64.

\section{Figure legends}

Figure 1: Technical features analysed. Above Top: technical features present on the flakes. Below Bottom: possible locations of the ridge of the bulb, the eraillure éraillure scars, hackles, ripples, inclination of the extraction axis, inclination of the striking platform and the type of striking platform.

Figure 2: Correspondence analysis of the experimental sample: left-handed knappers (L$\mathrm{x}$ ) are located above factor 2, while right-handed knappers (R-x) are located below this. All the samples are represented by triangles.

Figure 3: Left: Complete and broken flakes belonging to 34 groups of refits found from in level TD10.1 at the Gran Dolina site (Sierra de Atapuerca, Spain). Right: Archaeological refit groups GD8 and GD2 (photographs from López-Ortega, 2015).

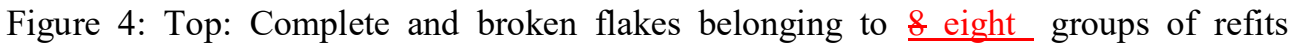
selected from levels Ja and M from the Abric Romaní Neanderthal site (Barcelona, Spain). Bottom: Archaeological refit groups AR1 (photograph from Vaquero et al., 2012) and AR8 (photograph by F. Romagnoli). 
Figure 5: Correspondence analysis of the entire set of experimental and archaeological samples. Triangles: experimental refit groups. + : refit groups from TD10.1, Gran Dolina $(G D)$. Circles: refit groups from levels Ja and M, Abric Romaní $(A R)$. (Axis 1= $19.7 \%$ eigenvalue; Axis $2=16.86 \%$ eigenvalue). The two axes represent $36.56 \%$ of the total.

Figure 6: Correspondence analysis of the experimental and archaeological samples, selecting just the archaeological refit groups with $\underline{5 \text { five }}$ or more flakes. Triangles: experimental refit groups. +: the only refit group from TD10.1 (GD29) with $\underline{5 \text { five }}$ flakes. $\underline{\text { Circles: }}$ the $\underline{8 \text { eight }}$ refit groups from Abric Romaní $(A R)$ with $\underline{5 \text { five }}$ or more flakes (Axis $1=28.36 \%$ eigenvalue; Axis $2=18.63 \%$ eigenvalue). The two axes represent $46.99 \%$ of the total. Shadowed individual (R_Nu) is positioned outside the sector of her real hand preference.

Figure 7. Correspondence analysis of the experimental sample downscaled to " $\mathrm{n}$ " flakes per knapper. Triangles: right-handed knappers, both for the original experimental sample (R_"x") and the subsample downscaled to "n" flakes (R_"n"). +: left-handed knappers, both for the original experimental sample (L_"x") and the subsample downscaled to "n" flakes (L_"n"). 7a. Downscaling the experimental subsample to $\underline{\underline{5}}$ five flakes (Axis $1=28.49 \%$ eigenvalue; Axis $2=18.53 \%$ eigenvalue). The two axes represent $47.02 \%$ of the total. $7 \mathbf{b}$. Downscaling the experimental subsample to $\underline{6 \text { six }}$ flakes (Axis $1=28.56 \%$ eigenvalue; Axis $2=17.11 \%$ eigenvalue). The two axes represent $45.66 \%$ of the total. 7 c. Downscaling the experimental subsample to 7 seven flakes (Axis $1=28.49 \%$ eigenvalue; Axis $2=15.83 \%$ eigenvalue). The two axes represent $45.66 \%$ of the total. 7 d. Downscaling the experimental subsample to $\underline{\& \text { eight }}$ 
flakes (Axis $1=26.65 \%$ eigenvalue; Axis $2=17.76 \%$ eigenvalue). The two axes represent $44.41 \%$ of the total. Shadowed samples are outside their real handedness position.

Figure 8: Correspondence analysis. Triangles: experimental subsample downscaled to $\underline{8}$ eight flakes. Circles: the only five archaeological refit groups with $\underline{\& \text { eight }}$ or more flakes, all from the Abric Romaní site. Experimental knapper R_Nu (shadowed) is outside her real hand preference position (Axis $1=30.93 \%$ eigenvalue; Axis $2=17.03 \%$ eigenvalue). The two axes represent $47.96 \%$ of the total.

Figure 9: Correspondence analysis. Triangles: experimental subsample downscaled to $\underline{8}$

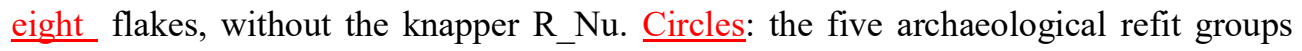
with $\underline{8 \text { eight }}$ or more flakes from Abric Romaní. (Axis 1=29.64\% eigenvalue; Axis 2= $18.11 \%$ eigenvalue). The two axes represent $47.75 \%$ of the total.

Table legend

Table 1: Number of flakes and broken flakes knapped by each participant during the experimental programme.

Table 2: Frequency of the technical features involved in handedness. The table includes the experimental and archaeological samples from Abric Romaní refit groups (AR). | R_"x" and L_"x": refit groups of right- and left-handed experimental knappers, respectively. 
Table 3: Frequency of the technical features involved in handedness. The table includes the experimental and archaeological samples from Gran Dolina-TD10.1 level (GD). 


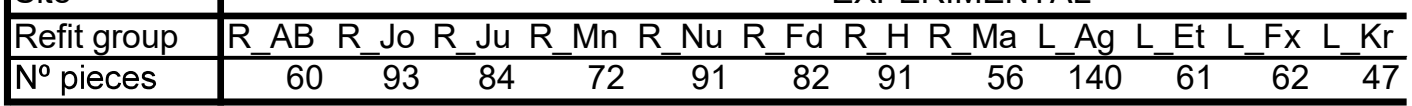




\begin{tabular}{|c|c|c|c|c|}
\hline PB & $\begin{array}{l}\text { TECHNICAL } \\
\text { FEATURES }\end{array}$ & VARIABLES & AR1 & AR2 \\
\hline \multirow{13}{*}{ VENTRAL SURFACE } & \multirow{2}{*}{ Ridge of the Bulb } & RIGHT & 8 & 2 \\
\hline & & LEFT & 2 & 5 \\
\hline & \multirow{3}{*}{ Location éraillure } & CENTRE & 1 & 2 \\
\hline & & RIGHT & 1 & 0 \\
\hline & & LEFT & 3 & 0 \\
\hline & \multirow{3}{*}{ Location hackles } & DISTAL & 0 & 0 \\
\hline & & RIGHT & 1 & 1 \\
\hline & & LEFT & 4 & 2 \\
\hline & \multirow{3}{*}{ Location ripples } & DISTAL & 2 & 0 \\
\hline & & RIGHT & 7 & 0 \\
\hline & & LEFT & 5 & 4 \\
\hline & \multirow{2}{*}{ Extraction axis } & RIGHT & 8 & 0 \\
\hline & & LEFT & 7 & 5 \\
\hline \multirow{8}{*}{$\begin{array}{l}\text { STRIKING } \\
\text { PLATFORM } \\
\text { SURFACE }\end{array}$} & \multirow{2}{*}{ Location impact point } & RIGHT & 10 & 1 \\
\hline & & LEFT & 5 & 3 \\
\hline & \multirow{3}{*}{$\begin{array}{l}\text { Inclination striking } \\
\text { platform }\end{array}$} & RIGHT & 7 & 1 \\
\hline & & LEFT & 5 & 2 \\
\hline & & SINUOUS & 0 & 0 \\
\hline & \multirow{3}{*}{$\begin{array}{l}\text { Morphology striking } \\
\text { platform }\end{array}$} & LINEAL & 5 & 1 \\
\hline & & PLAN & 16 & 6 \\
\hline & & POINTED & 0 & 0 \\
\hline
\end{tabular}




\begin{tabular}{|c|c|c|c|c|}
\hline PB & $\begin{array}{l}\text { TECHNICAL } \\
\text { FEATURES }\end{array}$ & VARIABLES & GD1 & GD2 \\
\hline \multirow{13}{*}{ 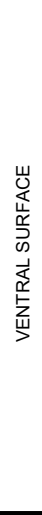 } & \multirow{2}{*}{ Ridge of the Bulb } & RIGHT & 1 & 0 \\
\hline & & LEFT & 1 & 3 \\
\hline & \multirow{3}{*}{ Location of éraillure } & CENTER & 0 & 0 \\
\hline & & RIGHT & 0 & 1 \\
\hline & & LEFT & 2 & 1 \\
\hline & \multirow{3}{*}{ Location of hackles } & DISTAL & 0 & 0 \\
\hline & & RIGHT & 1 & 1 \\
\hline & & LEFT & 1 & 0 \\
\hline & \multirow{3}{*}{ Location of ripples } & DISTAL & 1 & 0 \\
\hline & & RIGHT & 0 & 2 \\
\hline & & LEFT & 0 & 2 \\
\hline & \multirow{2}{*}{ Extraction axis } & RIGHT & 0 & 1 \\
\hline & & LEFT & 2 & 3 \\
\hline \multirow{8}{*}{ 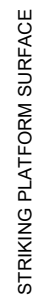 } & \multirow{2}{*}{$\begin{array}{l}\text { Location of impact } \\
\text { point }\end{array}$} & RIGHT & 2 & 3 \\
\hline & & LEFT & 0 & 1 \\
\hline & \multirow{3}{*}{$\begin{array}{l}\text { Inclination striking } \\
\text { platform }\end{array}$} & RIGHT & 0 & 3 \\
\hline & & LEFT & 0 & 1 \\
\hline & & SINUOUS & 0 & 0 \\
\hline & \multirow{3}{*}{$\begin{array}{l}\text { Morphology striking } \\
\text { plafform }\end{array}$} & LINEAL & 0 & 0 \\
\hline & & PLAN & 2 & 4 \\
\hline & & POINTED & 0 & 0 \\
\hline
\end{tabular}



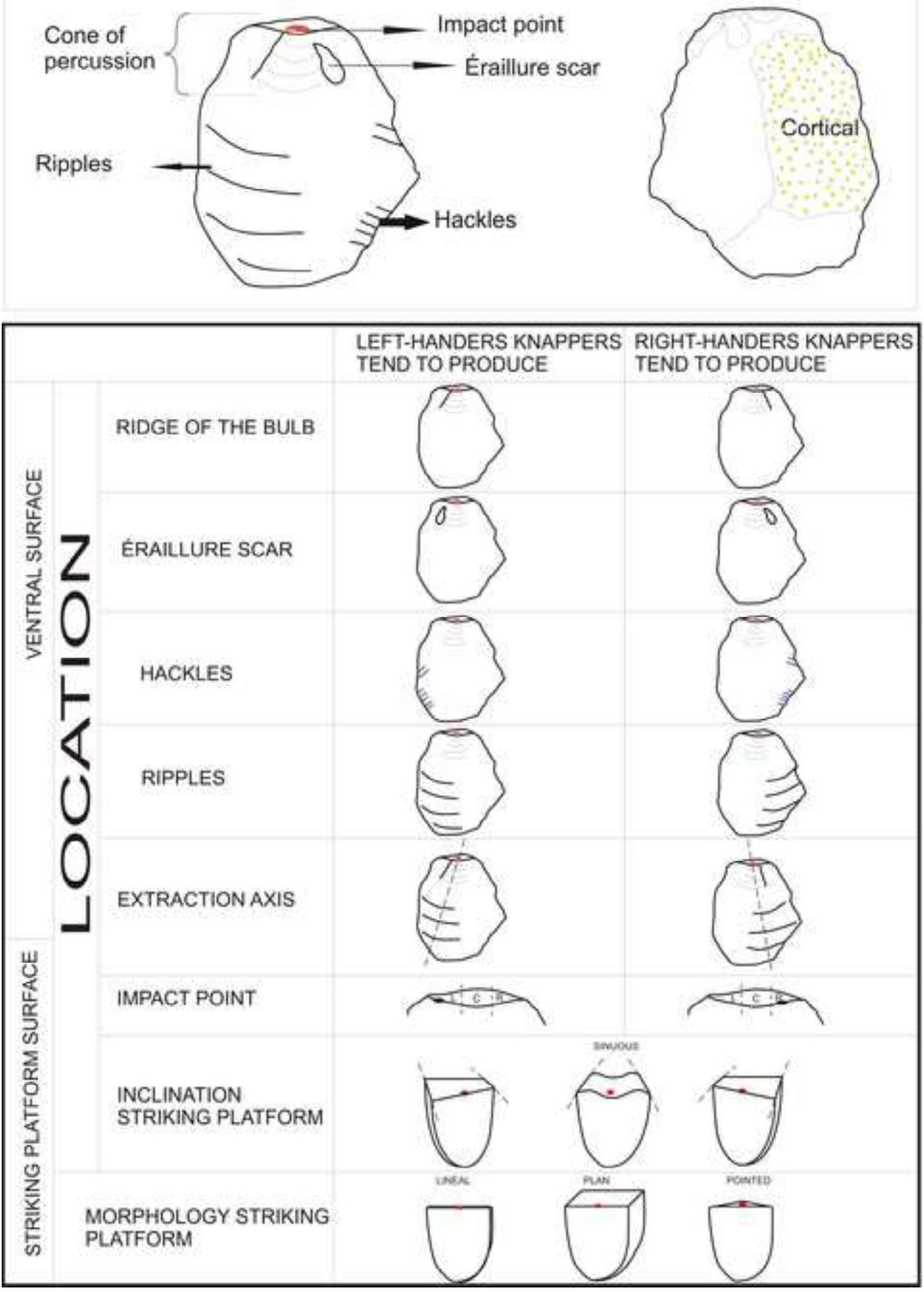


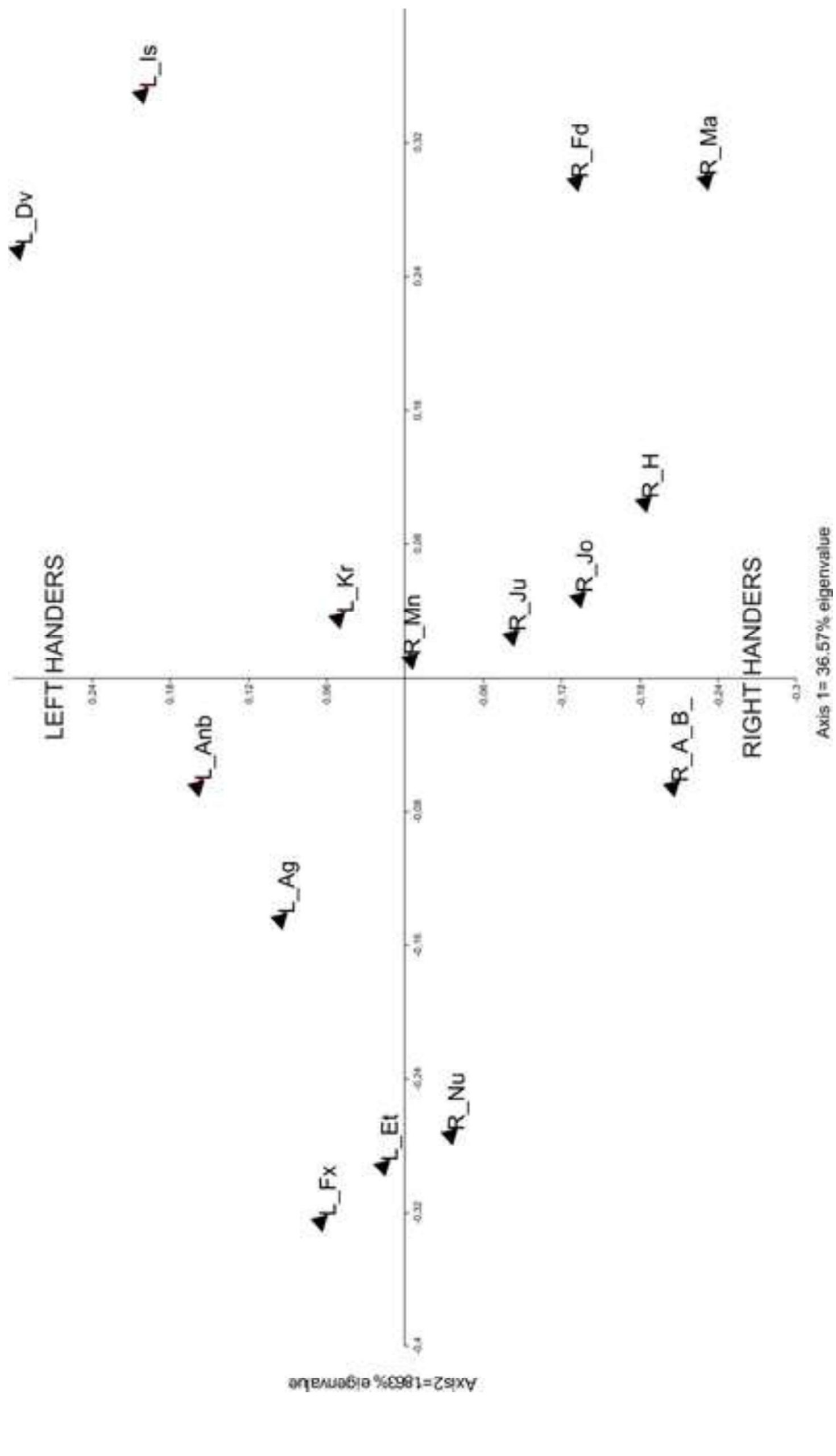


Click here to download high resolution image

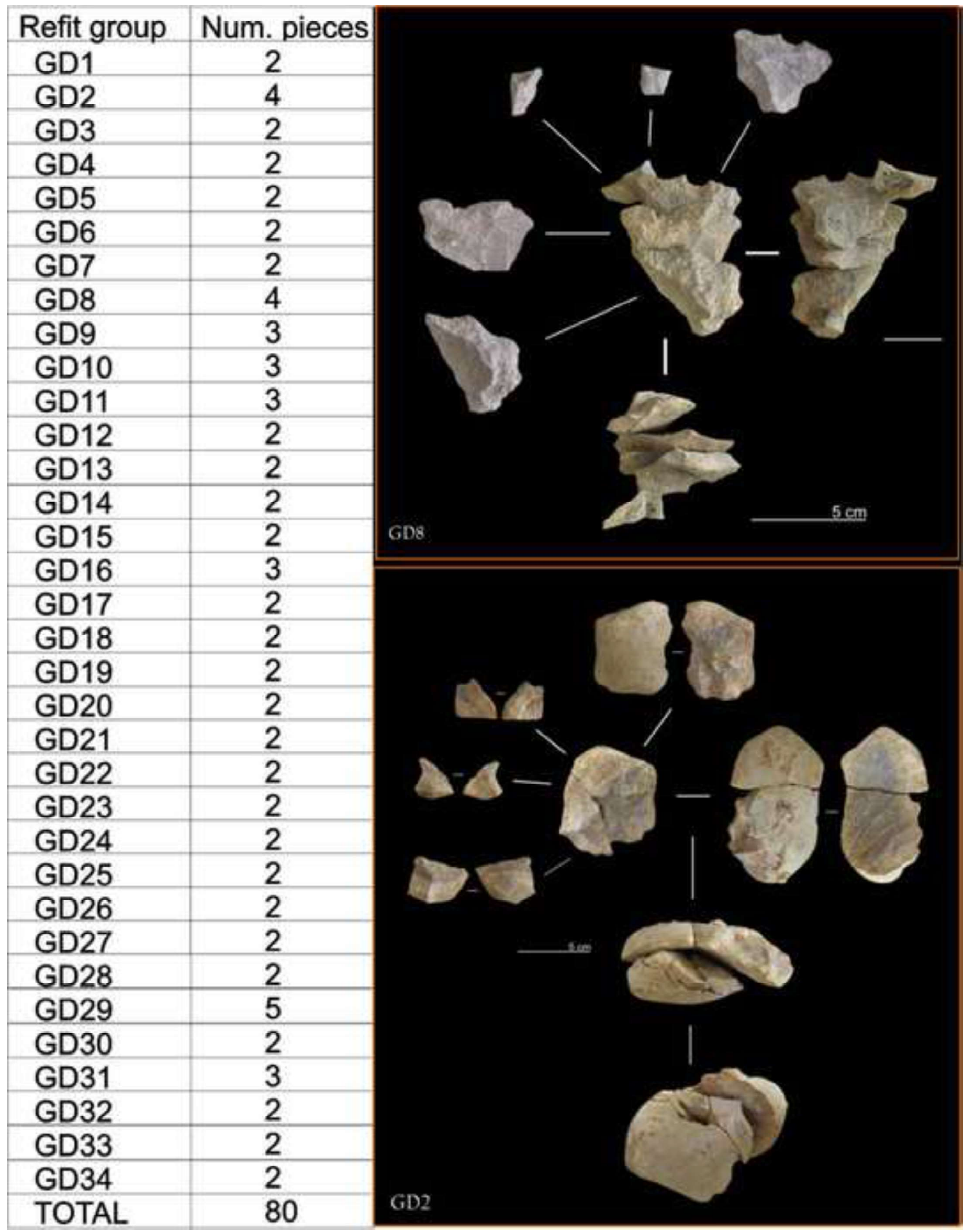




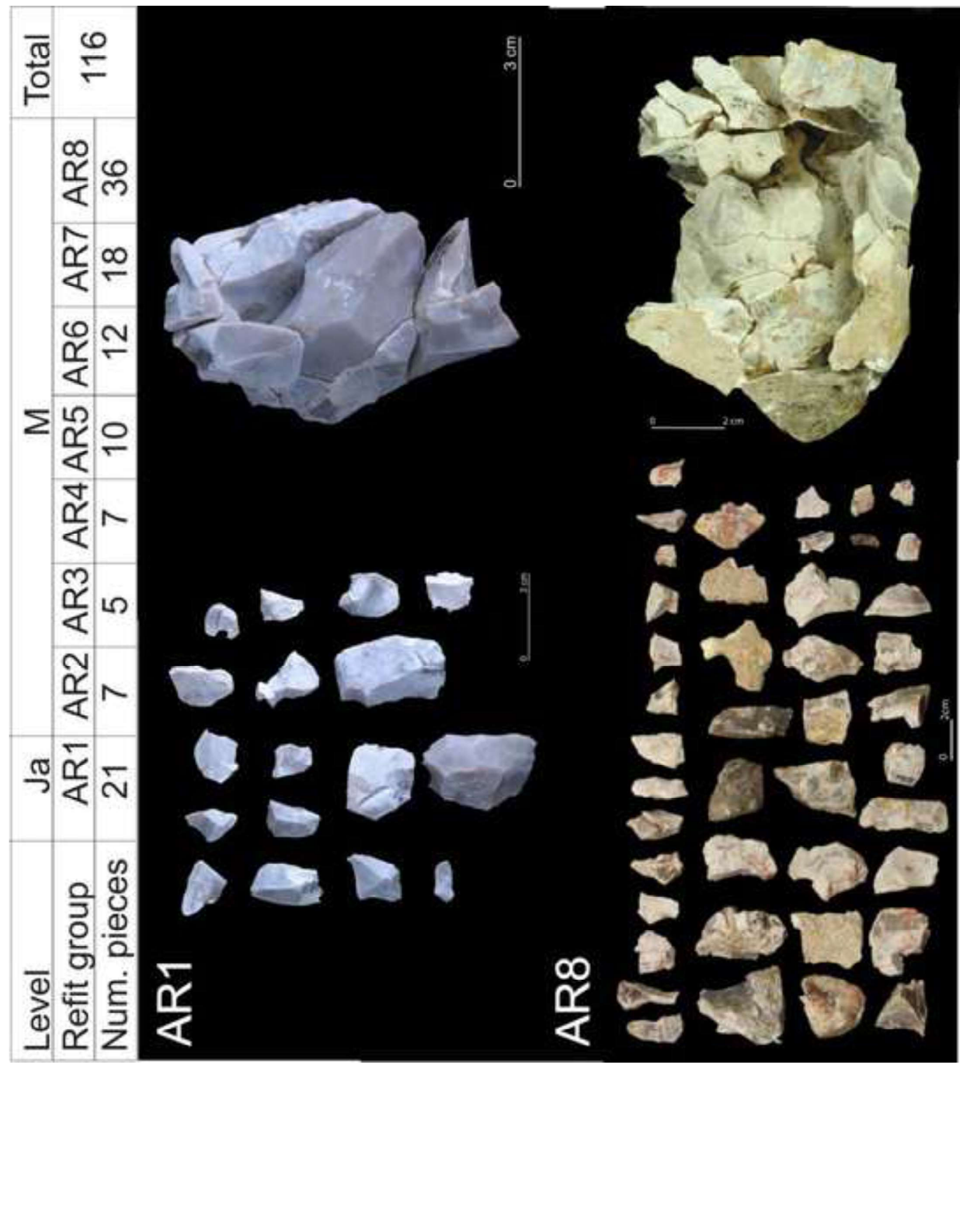




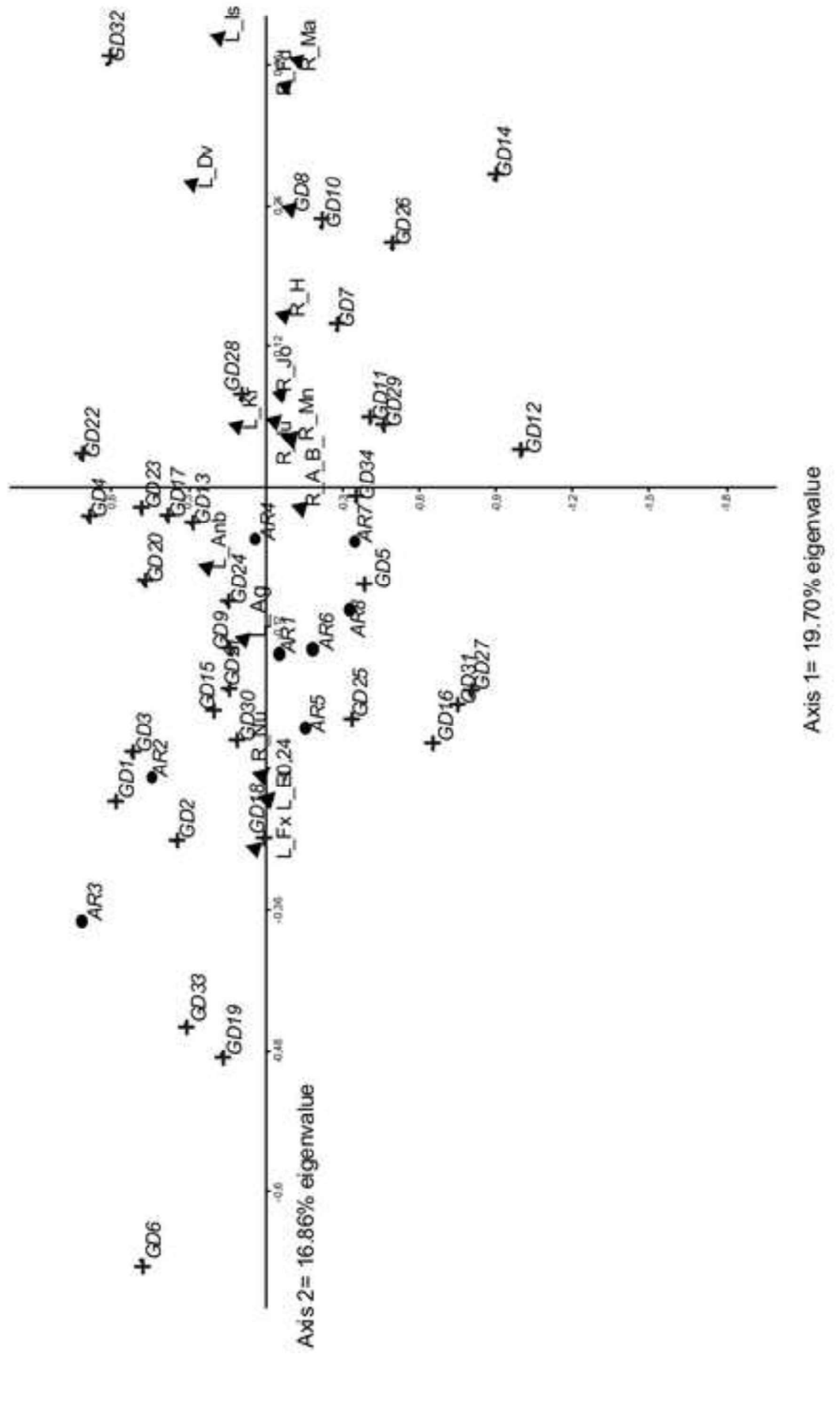




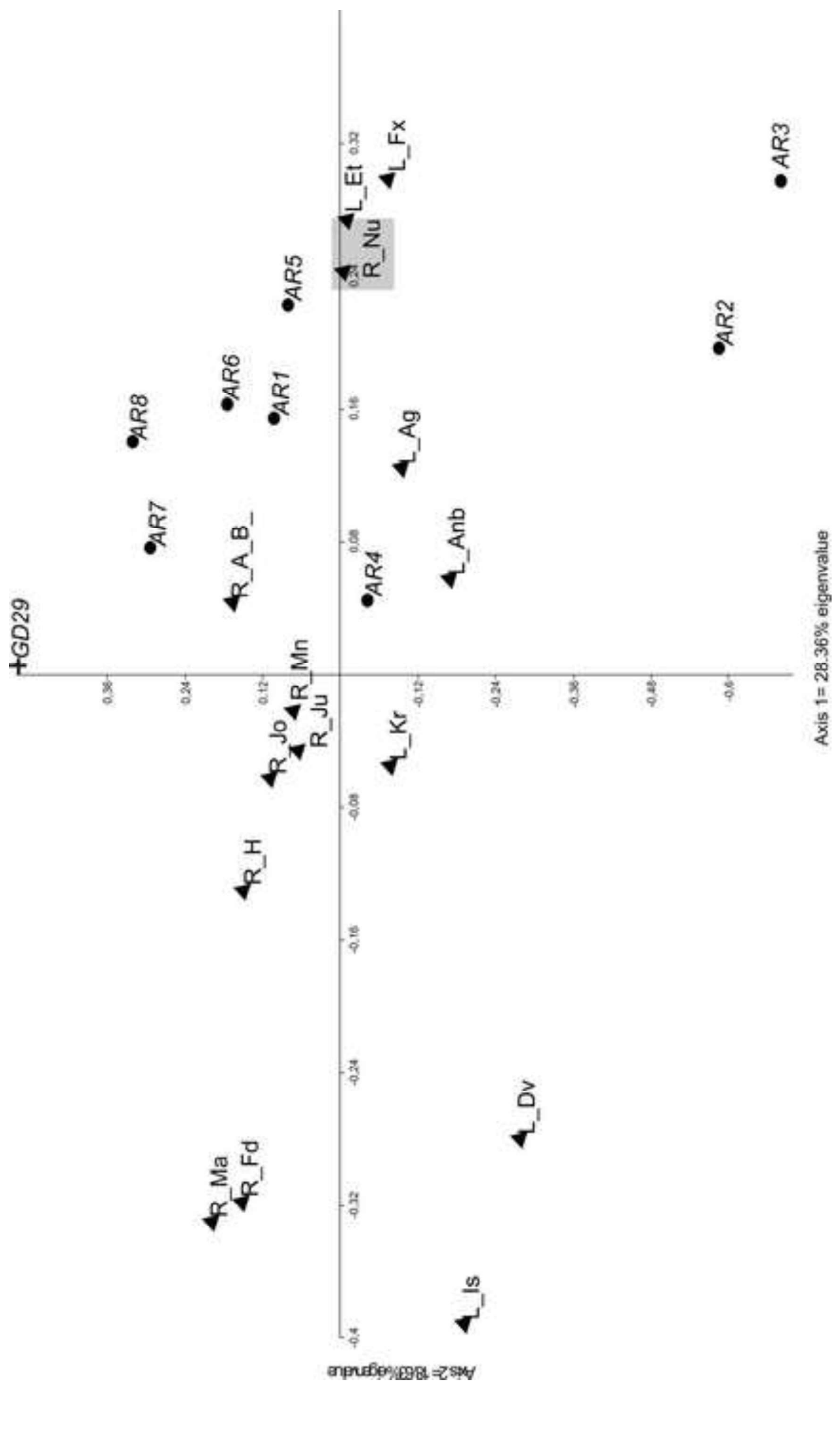



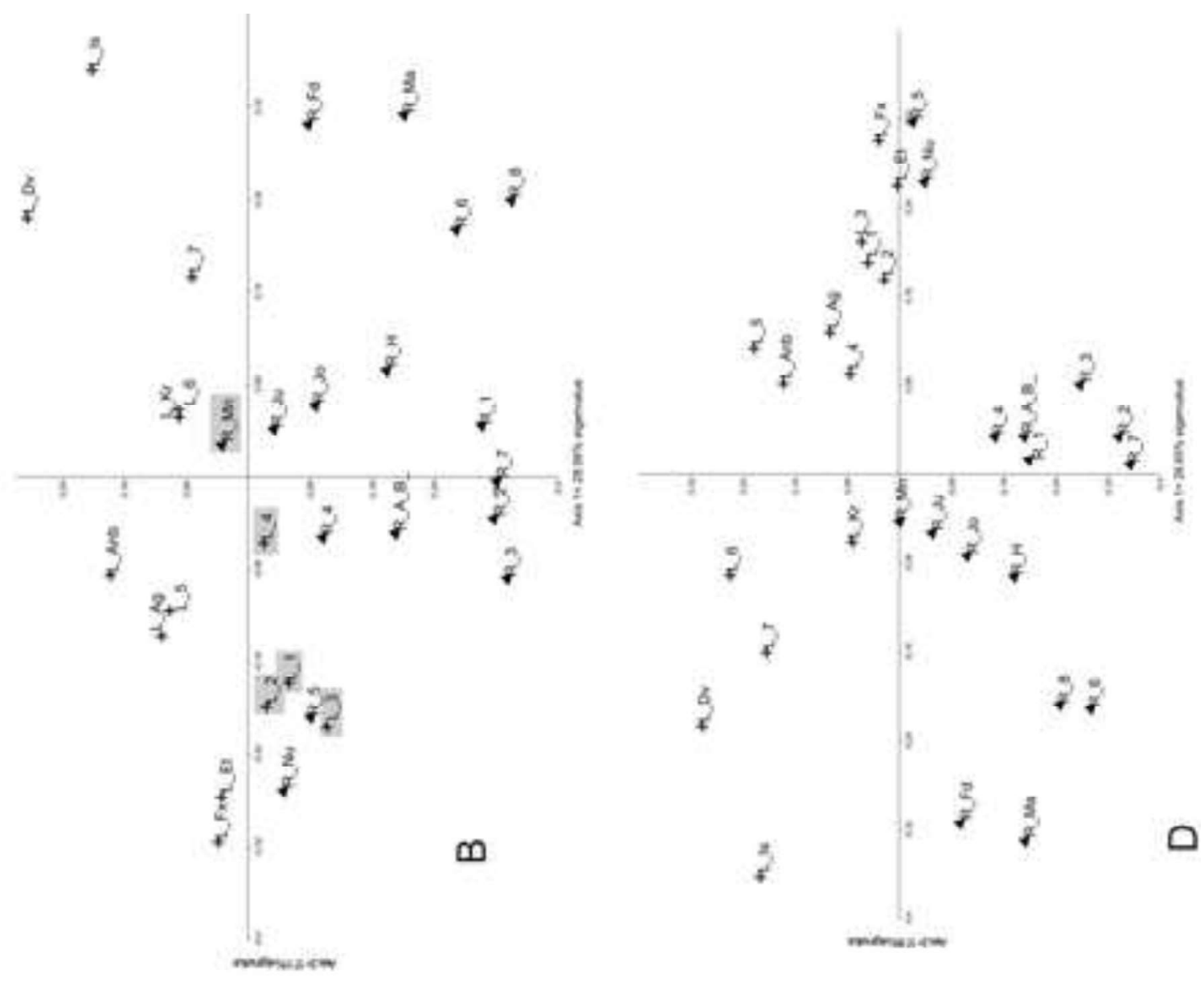

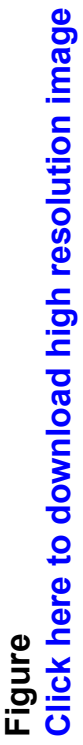

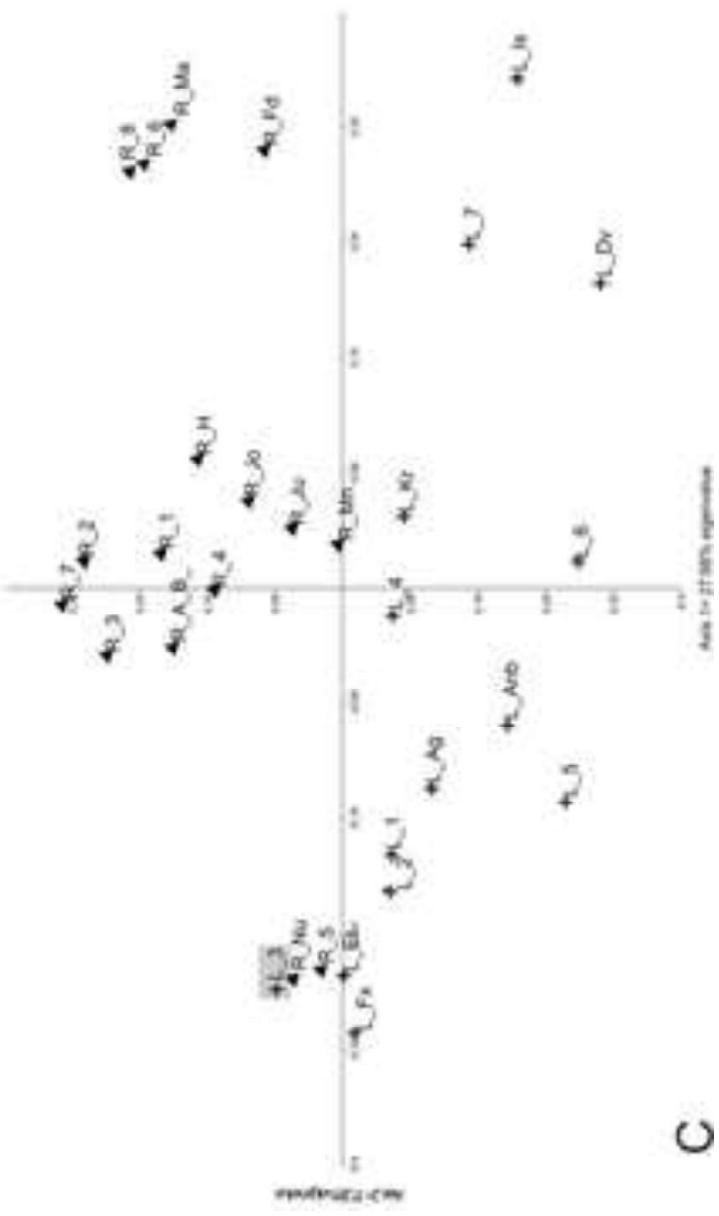




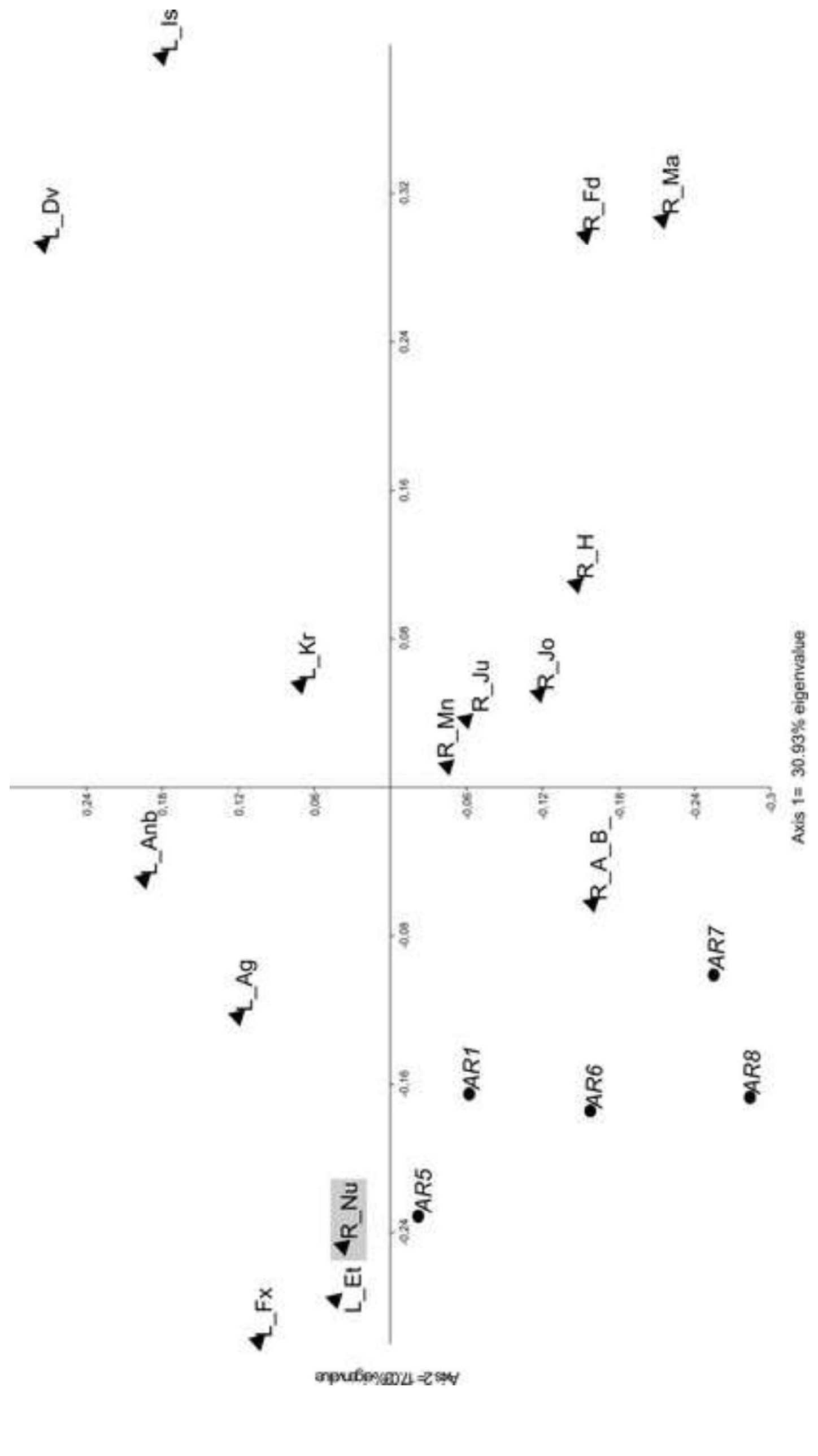




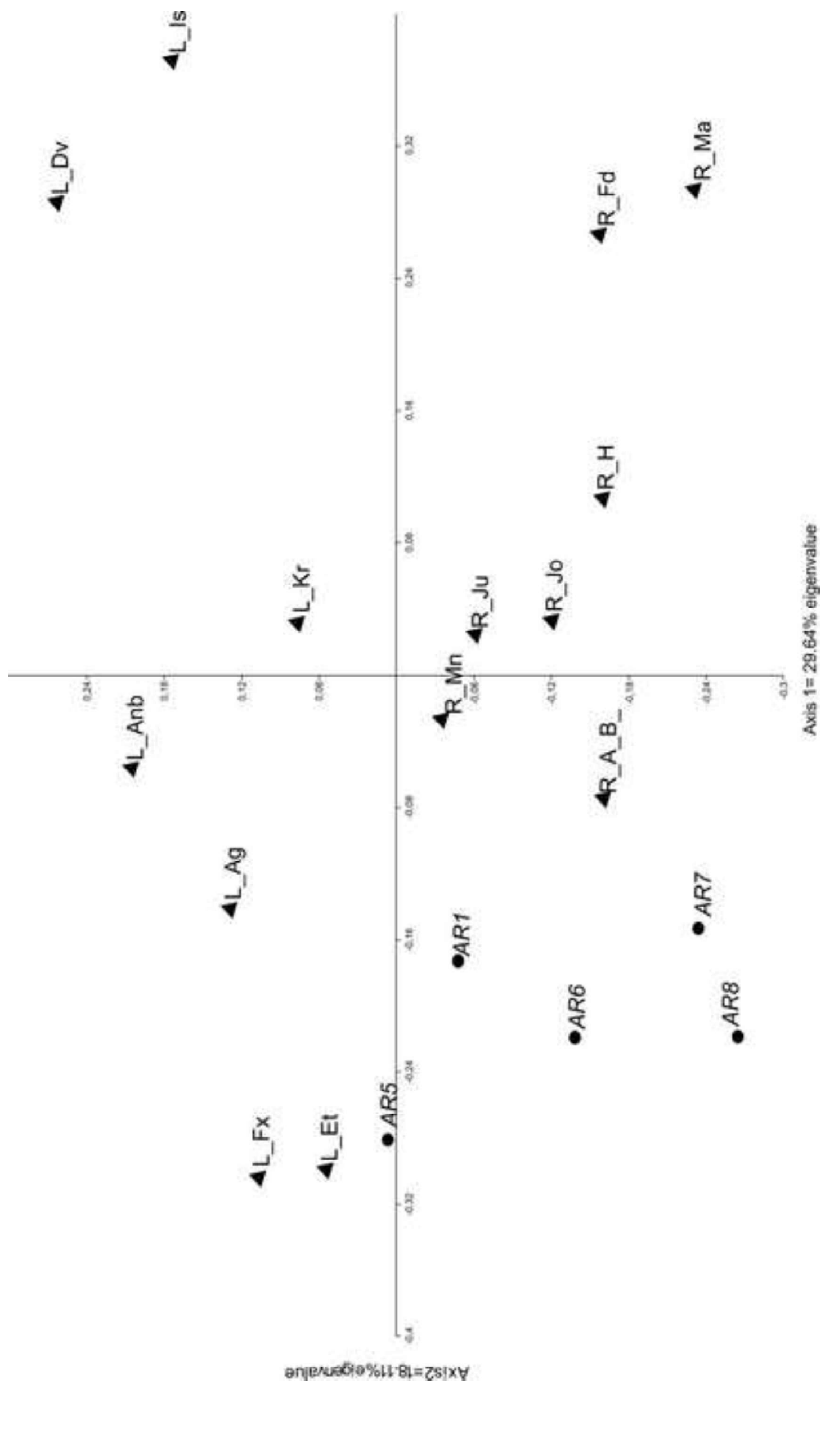

